\title{
Review
}

\section{Systematic Review Looking at the Use of Technology to Measure Free-Living Symptom and Activity Outcomes in Parkinson's Disease in the Home or a Home-like Environment}

\author{
Catherine Morgan ${ }^{\mathrm{a}, \mathrm{b}, \mathrm{c}, *}$, Michal Rolinski ${ }^{\mathrm{a}, \mathrm{c}}$, Roisin McNaney $^{\mathrm{b}}$, Bennet Jones ${ }^{\mathrm{d}}$, Lynn Rochester ${ }^{\mathrm{e}, \mathrm{f}}$, \\ Walter Maetzler ${ }^{\mathrm{g}}$, Ian Craddock ${ }^{\mathrm{b}}$ and Alan L. Whone ${ }^{\mathrm{a}, \mathrm{c}}$ \\ ${ }^{a}$ Translational Health Sciences, Bristol Medical School, University of Bristol, Bristol, UK \\ ${ }^{\mathrm{b}}$ School of Computer Science, Electrical and Electronic Engineering, and Engineering Mathematics, \\ Faculty of Engineering, University of Bristol, Bristol, UK \\ ${ }^{\mathrm{c}}$ Movement Disorders Group, Bristol Brain Centre, Southmead Hospital, North Bristol National \\ Health Service Trust, Bristol, UK \\ ${ }^{\mathrm{d}}$ Library and Knowledge Service, Learning and Research, Southmead Hospital, North Bristol \\ National Health Service Trust, Bristol, UK \\ ${ }^{\mathrm{e}}$ Institute of Neuroscience, Newcastle University, Newcastle Upon Tyne, UK \\ ${ }^{\mathrm{f}}$ Newcastle Upon Tyne Hospitals National Health Service Foundation Trust, Newcastle Upon Tyne, UK \\ ${ }^{\mathrm{g}}$ Department of Neurology, Christian-Albrechts University, Kiel, Germany
}

\begin{abstract}
.
Background: The emergence of new technologies measuring outcomes in Parkinson's disease (PD) to complement the existing clinical rating scales has introduced the possibility of measurement occurring in patients' own homes whilst they freely live and carry out normal day-to-day activities.

Objective: This systematic review seeks to provide an overview of what technology is being used to test which outcomes in PD from free-living participant activity in the setting of the home environment. Additionally, this review seeks to form an impression of the nature of validation and clinimetric testing carried out on the technological device(s) being used.

Methods: Five databases (Medline, Embase, PsycInfo, Cochrane and Web of Science) were systematically searched for papers dating from 2000. Study eligibility criteria included: adults with a PD diagnosis; the use of technology; the setting of a home or home-like environment; outcomes measuring any motor and non-motor aspect relevant to PD, as well as activities of daily living; unrestricted/unscripted activities undertaken by participants.
\end{abstract}

\footnotetext{
${ }^{*}$ Correspondence to: Dr. Catherine Morgan, Movement Disorders Group, Bristol Brain Centre, Southmead Hospital, NBT, Bristol, BS10 5NB, UK. Tel.: +44 07970 657958; E-mail: catherine.morgan@bristol.ac.uk.
} 
Results: 65 studies were selected for data extraction. There were wide varieties of participant sample sizes ( $<10$ up to hundreds) and study durations ( $<2$ weeks up to a year). The metrics evaluated by technology, largely using inertial measurement units in wearable devices, included gait, tremor, physical activity, bradykinesia, dyskinesia and motor fluctuations, posture, falls, typing, sleep and activities of daily living.

Conclusions: Home-based free-living testing in PD is being conducted by multiple groups with diverse approaches, focussing mainly on motor symptoms and sleep.

Keywords: Parkinsonian disorders, basal ganglia diseases, technology, algorithms, patient outcome assessment

\section{INTRODUCTION}

Parkinson's disease (PD) is a chronic, progressive, disabling disorder of the central nervous system with a wide heterogeneity of clinical presentations and rates of progression. It is the second most common neurodegenerative disease, with the Global Burden of Disease Study [1] estimating a worldwide prevalence of around 6.1 million people.

PD is characterised by a large variety of motor symptoms (including bradykinesia, rigidity, tremor and dyskinesia) and non-motor symptoms (including sleep disturbance, cognitive impairment, genitourinary dysfunction, fatigue and pain) [2]. PD is a complex disease exerting a large burden upon patients and their carers, and financially upon healthcare systems [3].

\section{Issues with clinical rating scales}

The MDS-UPDRS (Movement Disorder SocietySponsored Revision of the Unified Parkinson's Disease Rating Scale) [4] is the current gold-standard way of measuring disease severity in PD. It is a revised version of its predecessor clinical rating scale, simply called the UPDRS. The MDS-UPDRS has four parts, numbered I (with sub-sections A and B), II, III and IV, looking at non-motor and motor experiences of daily living, motor examination and motor complications. Parts IB and II are completed by the patient; otherwise the scale is completed by the rater. Sections or sub-sections of the MDS-UPDRS are frequently used in trials as primary outcome measures. The MDS-UPDRS is a valid [5] tool to measure a wide variety of different aspects of PD. However, it is also arguably a subjective [6], non-linear [7] scale which is biased toward certain aspects of the condition and which displays a 'floor effect' which renders it insensitive to early-stage disease [8]. In addition, the inter-rater variability of the MDS-UPDRS part III is up to 16 points [6] - to illustrate how substantial this variability is, it is notable that a change in UPDRS motor scores of 11 points in one person given a novel therapy in a clinical trial would represent a large clinically important difference (CID) and of about 3 points a minimal CID [9]. The MDS-UPDRS is predominantly used for clinical trials comparing therapeutic effects between groups on treatment versus placebo, to track longitudinal changes in PD cohorts over time or to guide clinical decision-making at the individual level in specific circumstances. However, the scale is not validated to permit comment upon what constitutes a clinically important difference (CID) in a single measured individual, given the test-retest variability at the single patient level is high. Similarly, scores comparing between small groups of individuals are also problematic and this, in-part, underlies the need for better ways of measuring outcomes. This is in order that true variability in symptoms, both intra-patient and inter-patient, can be measured with validity and accuracy. Moreover, the nature of the observed testing situation that the MDS-UDPRS requires means that confounds of observer bias and the 'Hawthorn Effect' (where aspects of performance are modified because the person is being observed) are introduced [10]. Finally, the single or episodically repeated 'snap-shot' of the person's symptoms and clinical signs is perhaps under-evaluating the symptomatology of some patients with $\mathrm{PD}$, which can fluctuate from day to day and hour to hour. Nevertheless, it remains the gold standard against which all other measures are compared, including sensor-based assessments.

\section{Technology in PD}

There is recognition within parts of the PD academic community, voiced by the International Parkinson and Movement Disorders Society Task Force on Technology, that technology could provide a rich source of granular data which captures the disease and treatment-related fluctuations of this complex condition [11]. Technological sensors have the potential to continuously and unobtrusively 
measure aspects of $\mathrm{PD}$, and the activities in the lives of those with PD, to give more reliable and objective evaluations of outcomes in PD.

The past 10-15 years has seen the emergence of a variety of technologies which have the potential to harness data to capture illness and health outcome measures, including smartphones $[12,13]$, wearable devices [11, 14], 'smart homes' (a home equipped with, e.g., lighting, heating, and electronic devices that can be controlled remotely by smartphone or computer) [15], advanced analytics and the Internet of Things (IoT) which is the interconnectivity via the internet between computing devices embedded in everyday objects [16].

Currently technology cannot replace may be able to assist the experienced clinician performing a detailed history and examination or a qualitative patient-reported experience of the disease. There are some symptoms which may prove extremely challenging to quantify using technology, such as pain, fatigue and rigidity. However, technology provides an opportunity to find a more sensitive and reliable way of measuring an individual's symptoms, which in turn could answer the need in clinical trials for improved ways of evaluating disease-modifying therapies [17]. In clinical practice, its use could be adjunctive to routine face-to-face patient-clinician interactions; it remains to be seen how much this would change management plan formulation although some reports are encouraging [18].

The advent of new technologies brings the threats which perhaps are inherent to the management of electronic data including data security. Close thought will need to be given with regards to considering the pathways towards regulatory approval for devices or platforms if these technologies are to be widely adopted in clinical trials or clinical practice [19].

\section{Testing in the home or home-like setting}

Generally, testing of new technologies takes place either in structured laboratory or clinic environments and/or in the home or home-like setting, otherwise known as the 'free-living' or naturalistic environment. Data can be collected from new digital devices through participants' scripted activities (undertaken in a pre-determined sequence according to a script) or unscripted activities (where the subject is able to freely choose their activities without being told to perform certain tasks). This review is interested in the data gathered from unscripted activities in free living; this data collection may be continuous or otherwise.
The choice of the home as a testing location to focus on for this review derives from perceiving the opportunities that this setting may bring to patients, clinicians and researchers. For people with PD, being tested at home could enable better appreciation of some activities of daily living (ADLs) which occur more naturally away from a clinic or lab environment [20], rare events such as falls [21], activities which impact upon wellbeing and quality of life [22] and outcomes such as sleep quality which are costly and logistically difficult to measure longitudinally in the clinic/lab. Technology deployed to the home could provide measurements to the clinician/researcher which would otherwise have required clinician time to obtain [23], have scalability to large numbers of people with PD remotely [24], and reduce the cost of clinic visit/clinical trial contacts [25]. An extrapolation is that the home setting could improve generalisability in outcome measure results, for example by increasing inclusivity towards those people living outside the radius of a clinical treatment unit. The aforementioned, however, are hoped for benefits and not yet of proven utility.

However, prior to employing technology-assisted in the home for longer-term use, hurdles include the proof that there will be comparability in detecting motor and other impairments when compared to in-clinic assessments [26], the documentation of acceptability of the technology in people with $\mathrm{PD}$, careful measures surrounding data management and navigating the technology towards regulatory approval [19].

\section{What this review adds to existing literature}

To our best knowledge, this is the first systematic review focussing on the evaluation of technology-assisted outcomes, using both wearable and non-wearable devices, from free living within the naturalistic environment in PD.

This systematic review aims to find out what is described in this area: what technologies are being used to measure which PD outcomes in what nature of ecological environment, and to give an idea of how the technologies are being clinimetrically tested and validated. We wish to highlight the areas where future development is needed in order to produce a fully-validated and clinically-relevant set of outcomes measurable in PD from a person's own home, using minimally intrusive and continuous monitoring. 


\section{METHODS}

A systematic review of all articles published from January 2000 until May 2018 was conducted using the following information sources: Medline, Embase, PsycInfo, Cochrane Database of Systematic Reviews and Cochrane Central Register of Controlled Trials and Web of Science.

The population being studied is people with $\mathrm{PD}$; the intervention is the use of technology/technological devices to measure activities in the home or home-like environment; there is no specific comparator; the outcomes being measured are symptoms of PD and also activities of daily living evaluated from the free-living of the participants. A review protocol is available at https://researchinformation.bris.ac.uk/en/publications [27]; the systematic review is registered in the International Prospective Register of Systematic Reviews, Prospero, under the identification CRD42018095479.

A combination of MeSH (Medical Subject Headings) terms and keywords were used in the search strategy. The authors borrowed from the published search strategy for a previous systematic review [14] and added additional pertinent terms when devising their strategy. Three blocks of these search terms were introduced and connected in the search strategy: the first relating to the condition of PD, for example "Parkinsonian disorders," "basal ganglia diseases,"; the second to capture the concept of technology terms related to PD assessment, for example "technology," "sensor," "machine learning," "accelerometer"; the third was related to the home or a home-like environment as the setting of the study, for example "home," "naturalistic," "free living". The full list of search terms is available in Supplementary Table 1.

The flowchart for study identification through to the studies included for data extraction, according to the PRISMA (Preferred Reporting Items for Systematic Reviews and Meta-Analyses) statement, is shown in Fig. 1. After identifying and de-duplicating the references from the sources mentioned above, the review was conducted in three stages:

Stage 1: Abstract screening

The studies' abstracts were screened by C.M. with $10 \%$ of the abstracts randomly selected and screened by an independent reviewer, M.R., to check for accuracy. The criteria for the articles included in the next step were: the population of PD and the use of technology as part of the study.

Stage 2: Full-text screening and assessment to determine eligibility to be included in this review

All of the full-text studies were read and assessed for eligibility by C.M., $10 \%$ of these studies were

Table 1

Sample size numbers indicating number of participants participating in free-living elements of selected studies

\begin{tabular}{|c|c|c|}
\hline Sample size & Number of studies & Studies \\
\hline Fewer than 10 & 12 & $\begin{array}{l}\text { Cereda et al.., } 2010 \text { [74], Das et al.., } 2012 \text { [68], Godfrey et al.., } 2016 \text { [62], } \\
\text { Nakae et al.., } 2011 \text { [78], Pastorino et al.., } 2013 \text { [80], Perez-Lopez et al.., } \\
2015 \text { [81], Raknim et al.., } 2016 \text { [44], Stack et al.., } 2016 \text { [47], Vega et al.., } \\
2016 \text { [48], Wallace et al.., } 2013 \text { [32], Weiss et al.., } 2011 \text { [65], White et } \\
\text { al.., } 2007 \text { [50] }\end{array}$ \\
\hline $10-49$ & 32 & $\begin{array}{l}\text { Battista et al.., } 2018 \text { [66], Bayes et al.., } 2018 \text { [83], Bhidayasiri et al.., } 2016 \\
\text { [31], Bhidayasiri et al.., } 2017 \text { [33], Cai et al.., } 2017 \text { [29], Cancela et al.., } \\
\text { 2011 [51], Cancela et al.., } 2014 \text { [54], Cavanaugh et al.., } 2012 \text { [49], Cole } \\
\text { et al.., } 2010 \text { [40], Cole et al.., } 2014 \text { [39], El Gohary et al.., } 2010 \text { [69], El } \\
\text { Gohary et al.., 2014 [59], Fisher et al.., } 2016 \text { [85], Haertner et al.., } 2018 \\
\text { [57], Hale et al., } 2010 \text { [75], Iluz et al., } 2014 \text { [58], Johansson et al., } 2018 \\
\text { [42], Liddle et al., } 2014 \text { [43], Madrid-Navarro et al., } 2018 \text { [89], Mancini } \\
\text { et al., } 2015 \text { [53], Ramsperger et al., 2016 [45], Rodriguez-Molinero et } \\
\text { al., 2015 [84], Rodriguez-Molinero et al., } 2018 \text { [82], Roy et al., 2011 } \\
\text { [38], Roy et al., 2013 [37], Sama et al., 2014 [56], Skidmore et al., } 2008 \\
\text { [70], Sringean et al., 2016 [93], Sringean et al., } 2017 \text { [94], Tzallas et al., } \\
\text { 2014 [55], Van Uem et al., 2018 [71], Van Wegen et al., 2018 [86] }\end{array}$ \\
\hline $50-99$ & 13 & $\begin{array}{l}\text { Adams et al., } 2017 \text { [87], Arroyo-Gallego et al., } 2018 \text { [30], Wallen et al., } \\
2015 \text { [73], Cheng et al., } 2017 \text { [34], Del Din et al., 2016 [64], Gros et al., } \\
2015 \text { [90], Klingelhoefer et al., } 2016 \text { [91], Lloret et al., } 2010 \text { [76], } \\
\text { Mancini et al., } 2018 \text { [60], Uchino et al., } 2017 \text { [95], Wallen et al., } 2014 \\
\text { [72], Wallen et al., } 2014 \text { [36], White et al., } 2009 \text { [77] }\end{array}$ \\
\hline 100 or more & 8 & $\begin{array}{l}\text { Cancela et al., } 2013 \text { [52], Cohen et al., } 2016 \text { [67], Del Din et al., } 2017 \text { [61], } \\
\text { Silva de Lima et al., } 2017 \text { [41], Silva de Lima et al., } 2018 \text { [46], Lim et } \\
\text { al., } 2010 \text { [35], Morris et al., } 2017 \text { [63], Prudon et al., } 2014 \text { [92] }\end{array}$ \\
\hline
\end{tabular}




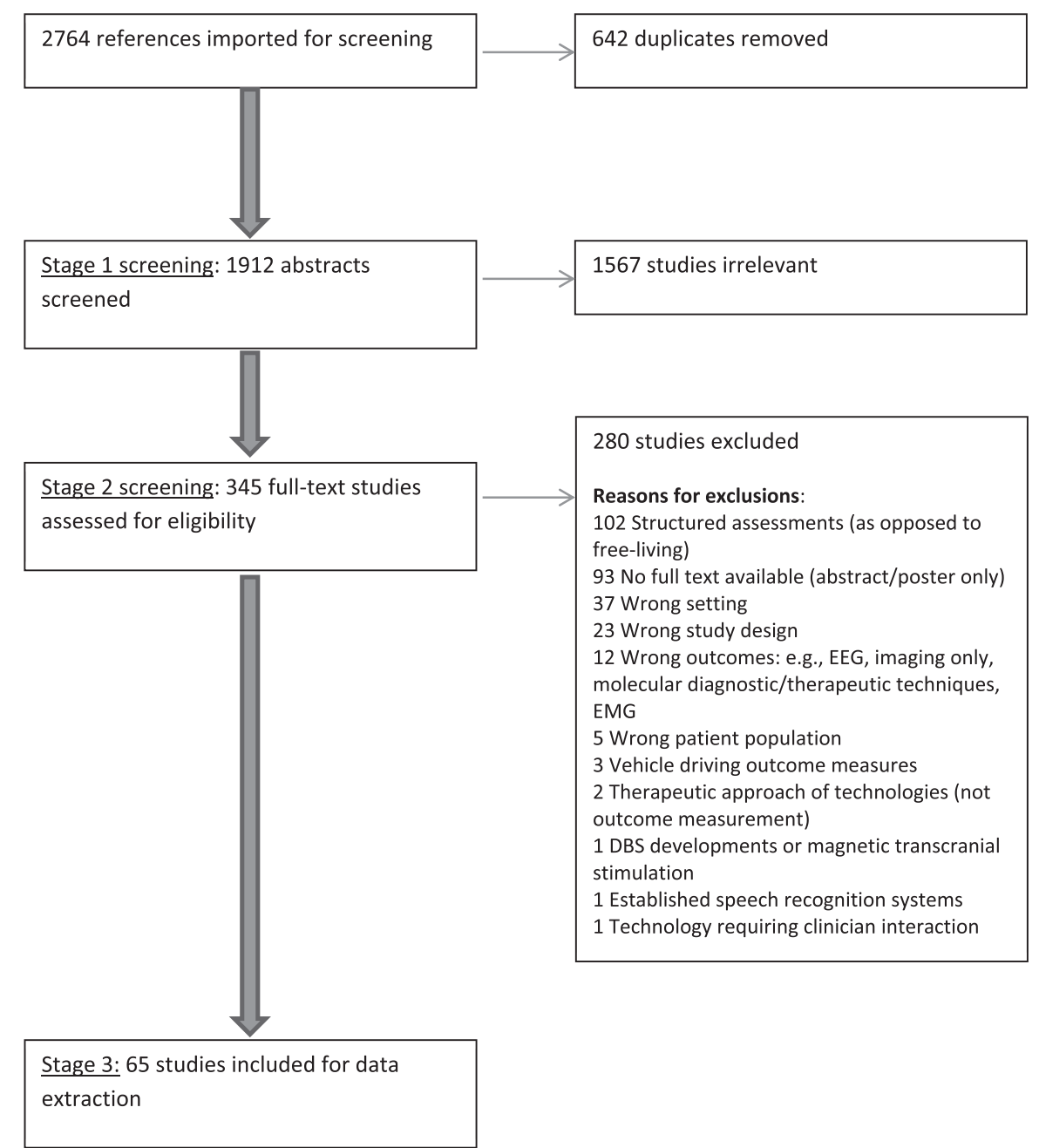

Fig. 1. PRISMA (Preferred Reporting Items for Systematic Reviews and Meta-Analyses) flowchart.

selected at random and assessed by an independent reviewer, M.R, to check for accuracy.

The criteria to include a study in the next step of data extraction included: the study included a population of adults with a PD diagnosis; technology was used, for example (but not necessarily including) wearable and/or non-wearable devices, wireless/remote sensing technology, machine learning and/or algorithm development; the setting included a home-like environment or home environment, including environments where participants can move freely; outcome was the measuring, assessing or testing of any motor and non-motor aspect relevant to PD, as well as ADLs; the study included unrestricted/unscripted activities undertaken by participants.
Regarding the full-text studies, exclusion criteria for the next evaluation step were:

- The sole use of electromyography and/or electroencephalography (EEG) to generate outcomes;

- The sole use of questionnaires/scales;

- The sole use of technology requiring clinician interaction (e.g., remote consultations);

- The sole use of sphygmomanometers (i.e., blood pressure cuff with intermittent readings) to look at autonomic function;

- Genetic/Molecular diagnostic/therapeutic methods;

- Structured assessments in the home (as opposed to free living); 
- Vehicle driving outcome measures;

- Imaging techniques only;

- Established speech recognition systems;

- New developments in deep brain stimulation (DBS);

- Magnetic transcranial stimulation only;

- Study design not involving testing of technology on participants at home (e.g., review, protocol, acceptability testing only);

- Articles not written in English language

- Therapeutic approaches of technologies only (as opposed to outcome measurement); and

- Full text was not available (through our University's library access, and with cross-check using a mainstream widely-available search engine, Google Scholar).

The exclusion criteria were chosen to facilitate the inclusion only of studies which matched the review's aims of evaluating the measurement of free living outcomes in PD in a free-living environment, specifically in the home as opposed to in a car for example.

A list of excluded manuscripts is provided as a supplement to this paper (Supplementary Table 2).

Stage 3: Data extraction from the included studies

Full evaluation of the included studies was completed by C.M., with independent evaluation by M.R. of $20 \%$ of randomly selected studies. Any mismatches between the two reviewers were discussed face-to-face and resolutions were agreed by both parties.

Information on several pre-selected aspects was extracted using a customised table specifically designed for this review in Covidence systematic review software [28]. The aspects selected were intended to give the reader a grasp of the type of technologies being used, which aspects of PD were being measured and in what nature of location. This included the study design and any prior work to validate the technology in PD which appeared to have been carried out. To give an idea of the aspects of PD being evaluated, it was delineated whether motor, non-motor or ADLs (or a combination) were being measured, and whether single or multiple aspects/symptoms of PD were analysed. Of particular interest to this review is the location of technology testing - whether at home or in a homelike setting — and additionally the number of sensors (single or multiple) being used. The phrase 'homelike setting' is taken to mean a place which closely resembles a participant's real home in terms of furniture/appliances where a participant can stay and move/live freely, but which is not in fact their true home.

Data was also extracted on each study's inclusion and exclusion criteria, duration of home-based testing and the sample size used in each article.

Finally, details of the technologies used, and the outcomes generated, was collected. Largely, given that these studies were observational and exploratory in design, clinimetric properties such as repeatability and responsiveness to a pharmacological intervention were not expected to feature heavily in the studies' design. However, any reported clinimetric properties (accuracy, responsiveness, reliability, test-retest agreement and agreement with the goldstandard clinical rating scale in PD) were extracted, whether those gathered from direct testing in the home/home-like environment in the studies or those documented in the manuscripts relating to previous testing.

\section{RESULTS}

A total of 2764 studies were extracted by the search detailed above. After duplicates were removed, 1912 abstracts were screened by the authors. From these, 345 full texts were selected to be screened, of which 65 studies were included in this review.

An overview will be given about study designs used, the nature of the home/home-like environment in which the technologies were tested, the study sample size range and the duration of the studies. Subsequently, grouped by the metric(s) being measured, more detail about the outcome measurement, the nature of the technology used in measuring it, any validation undertaken and finally the documented clinimetric properties of the technology will be outlined.

\section{Study design}

Of the 65 studies selected for data extraction, the study design was most frequently observational (57 out of $65,88 \%$ ). There were two papers detailing a case-control design whereby people with PD were directly compared to control participants when evaluating various parameters such as activity levels and keyboard typing metrics $[29,30]$. In two studies, technologies were being used in the home environment as outcome measures in clinical therapeutic trials [31, 32] and a further four were randomised controlled trials or sub-studies thereof [33-36]. 


\section{Nature of home-like environment}

Out of 65 studies, 61 described technology use in the participants' own homes. When the participants' actual home was not utilised, two studies described a ' $100-\mathrm{m}^{2}$ laboratory arranged to simulate a home environment' $[37,38]$ and two utilised a simulated 'apartment/home environment' $[39,40]$ as a test-bed.

\section{Sample size}

The number of participants used to test technological systems in a naturalistic environment varied greatly between studies. Almost half of the studies (32) used between 10 and 49 participants in home testing of their technologies. However, a significant number used fewer than 10 or more than 100 participants (12 and 8 studies respectively). Table 1 gives details about the numbers of study participants.

\section{Duration of home study}

Where the study duration was specified, the majority of the studies included in this review described testing of their sensors/technology over two weeks or less, however 10 studies detailed longer period of study time of up to a year [32, 34, 41-48]. Data from sensing technology was collected on more than one occasion by three studies. Cavanaugh et al. [49] used an ankle-worn wearable device to measure ambulatory activity levels. They compared the correlation between wearable sensor outcomes and clinical measures of gait and disease severity over a period of time (one year) by measuring ambulatory activity levels at the beginning and then again at the end of the year. Lim et al. [35] were investigating the impact of home cueing training on ambulatory activity monitoring outcomes over a period of 12 weeks at four specific times. White et al. [50] measured 24-48 hours of physical activity at 3 time points, separated by 7 days.

\section{Which PD outcomes were measured, by which technologies and how were these devices validated and clinimetrically tested?}

The individual metrics (e.g., tremor, bradykinesia) have been described in their own sections below, however it is important to note that frequently several metrics were tested by technologies within the same paper, and therefore those papers are described in more than one of the sub-sections below.
Gait

Gait, including freezing of gait, turning of gait and missteps, was evaluated by technologies in 19 studies included in this systematic review. Wearable technologies were used to measure this metric in 18 of the 19 papers, with the exception of Wallace et al. [32] who used in-depth video cameras to assess gait in the context of the impact of wearing strategicallyweighted vests on this metric. Smartphones were included in the 'wearable' category given that they are worn on a person in a pocket or similar in order to capture the movements which inform gait analysis; these devices were utilised by two groups [34, 44]. Five of the studies outlined a multiple wearable device platform with which to measure gait [51-55], although four of these papers were from the same group (Cancela et al). Accelerometers were used in all the wearable devices detailed in the studies; gyroscopes were added to accelerometry in the technology described in ten papers $[34,51-59]$ and magnetometers were identified to also have been used in two of these studies [56, 57]. Validation of the technology outcomes measuring aspects of gait was referred to in 17 of the studies. These validation efforts, prior to the use of the technology in the free-living setting (either carried out as part of the studies included in this review themselves, or in previous clearlyreferenced work), had taken place in laboratory-style settings where the activities were largely structured. Videotapes had been documented to have been used to provide 'ground truth' (real world accuracy provided by directing observing the activities; this can be achieved in a number of ways) to technology outcomes in 13 of the papers $[39,40,51-58,60-62]$, with instrumented walkways [61-64], motion analysis $[53,60]$, comparison with other similarly-positioned wearable devices [44] and direct researcher observation $[58,64,65]$ also used to validate the technology. Clinimetric properties, detailed in Table 2, showed that 16 studies evaluating gait either evaluated clinimetric properties of their technologies themselves or referenced relevant other/previous work. Ten of those papers gave accuracy statistics, whilst seven looked at agreement between the technology-assisted outcomes and other tools like the UPDRS [51, 53, 60, $65]$, or an instrumented walkway [61, 63, 64].

\section{Tremor}

Tremor was measured in 13 studies (either as a single metric or combined with other metrics). All of 


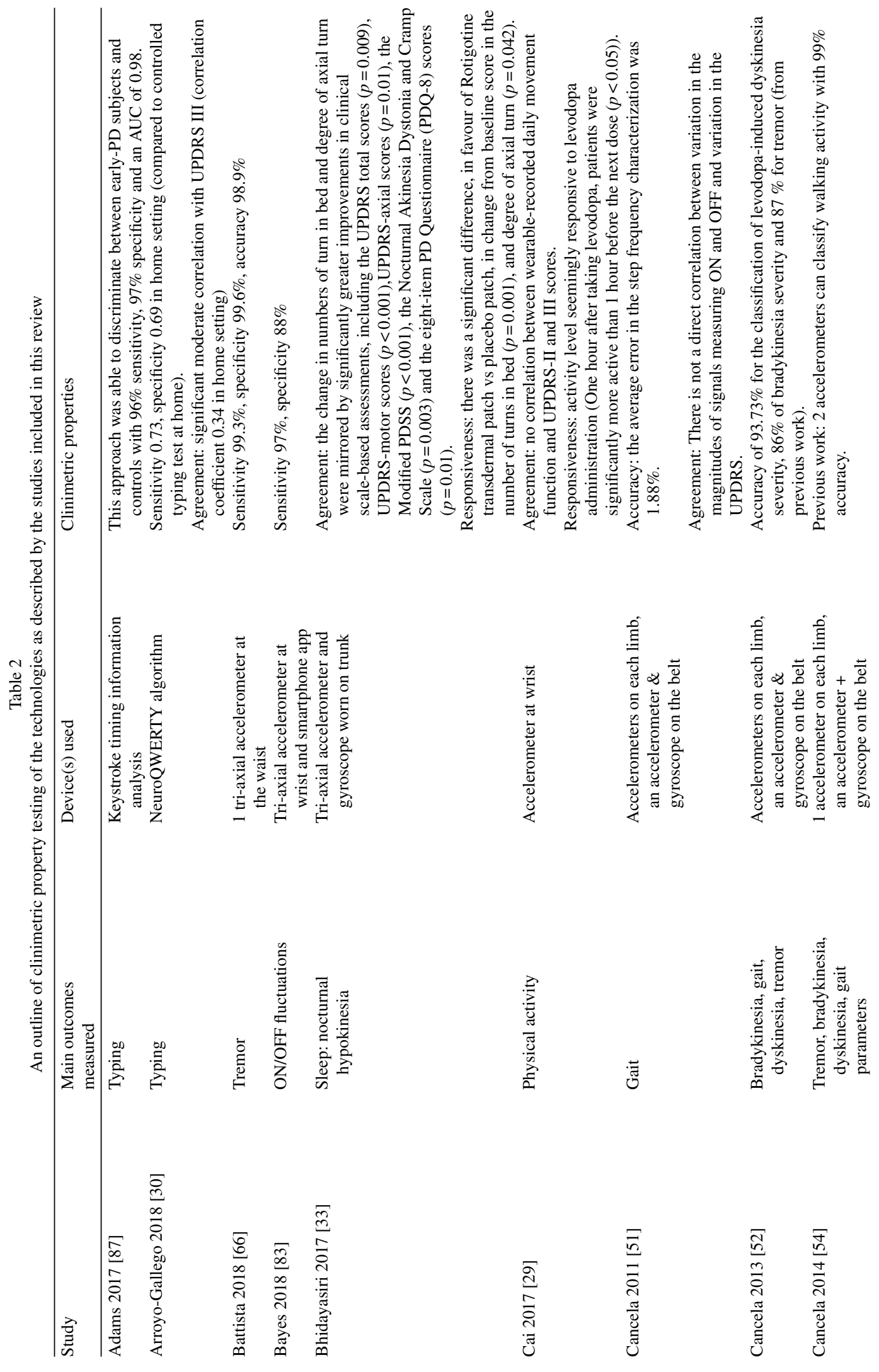



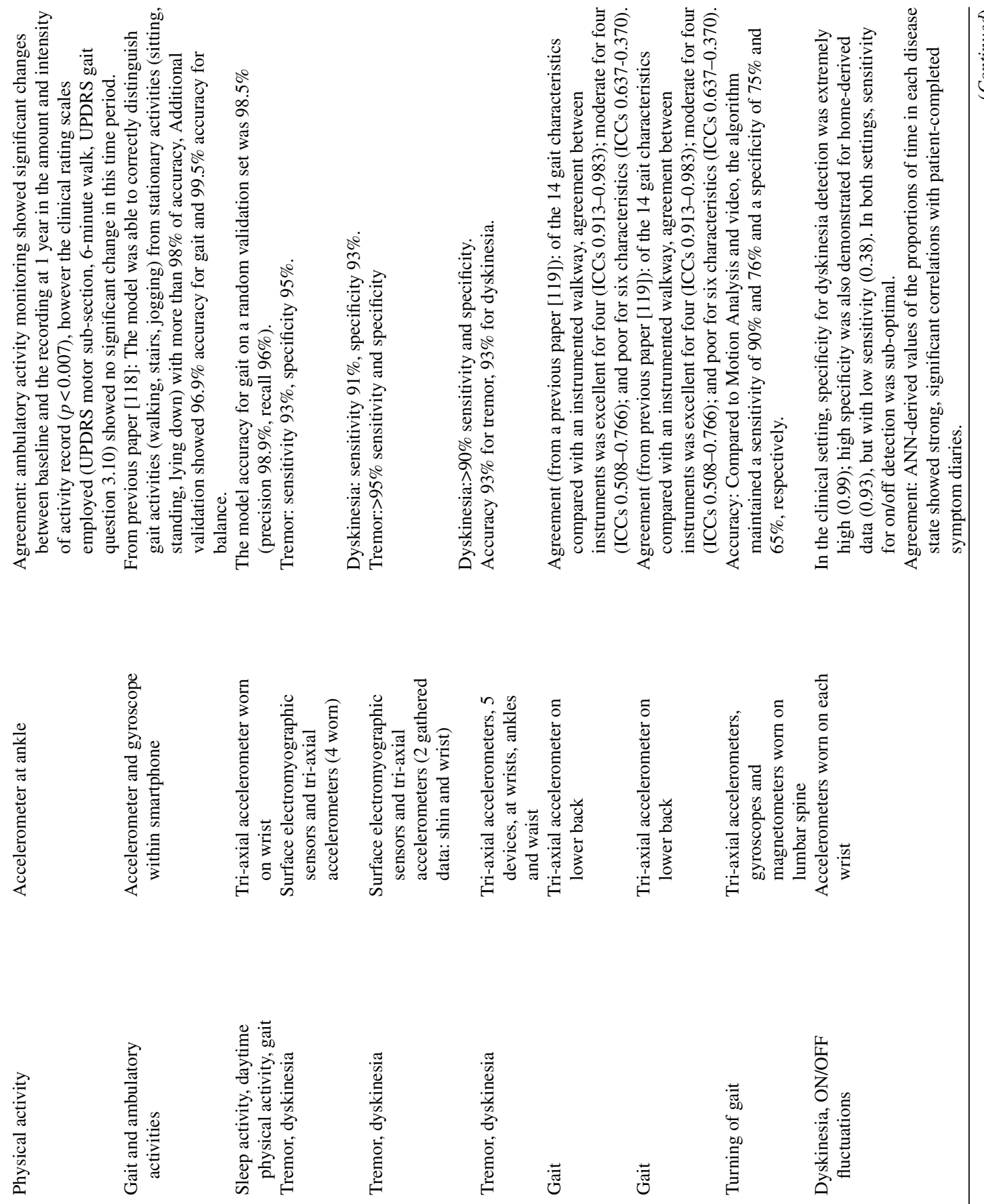

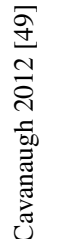

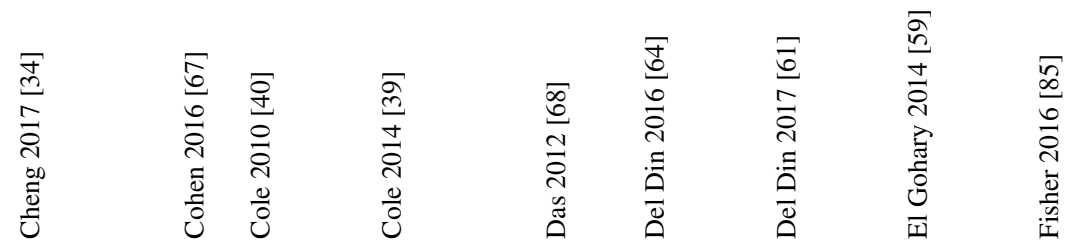




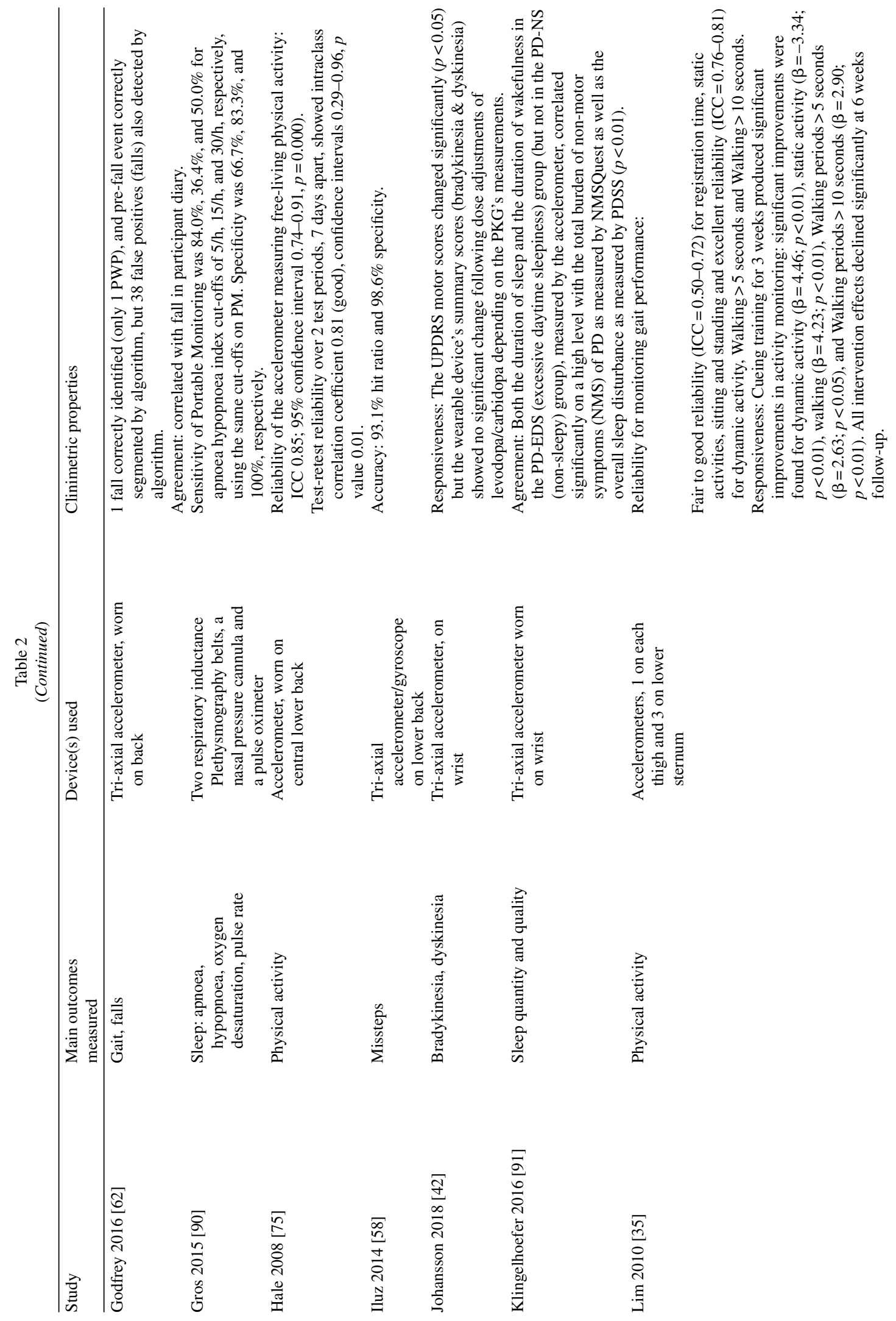




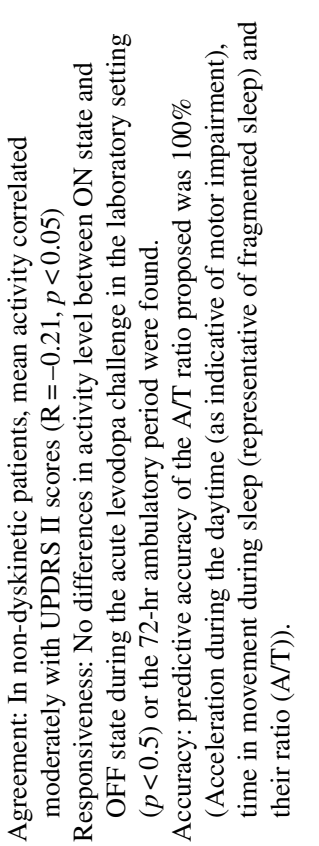

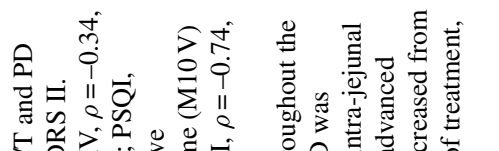

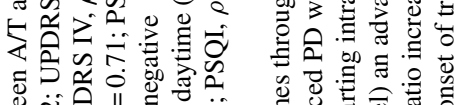

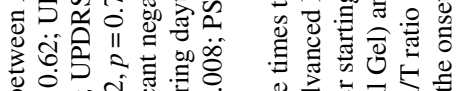

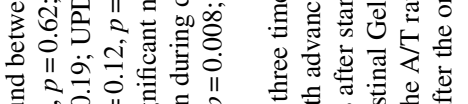
言的光 II.

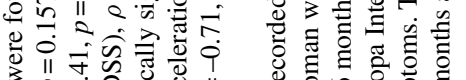

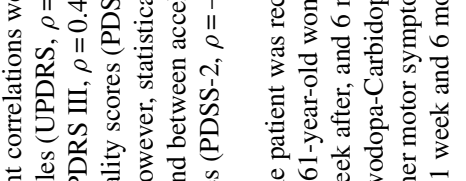

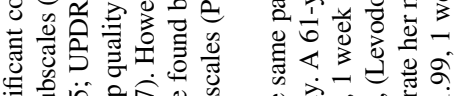

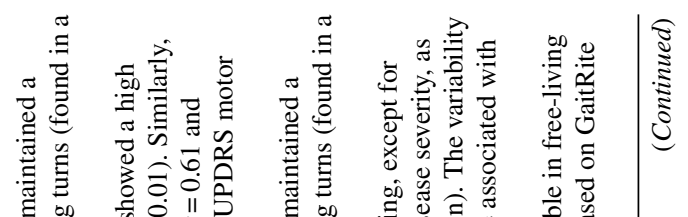

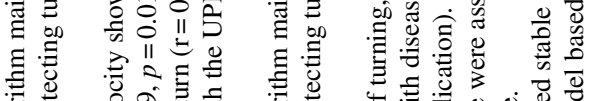

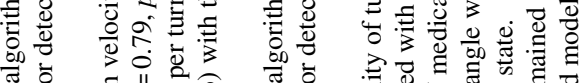

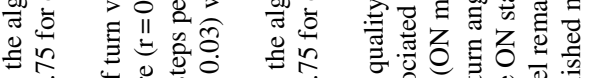

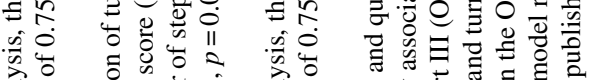

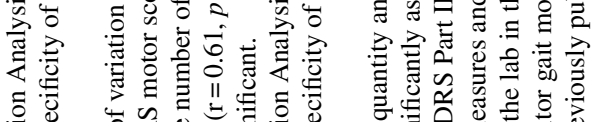

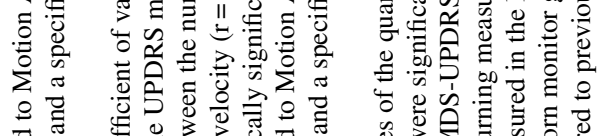

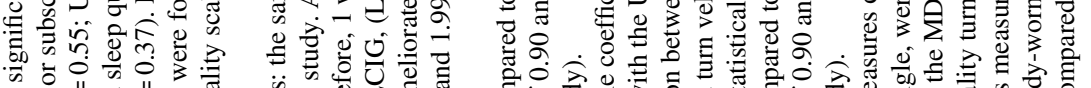

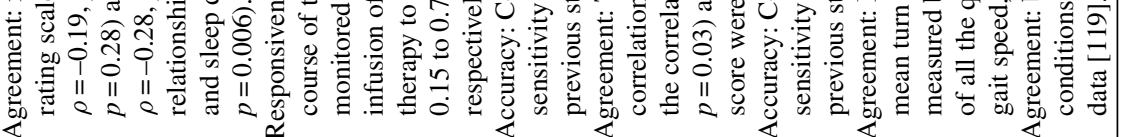
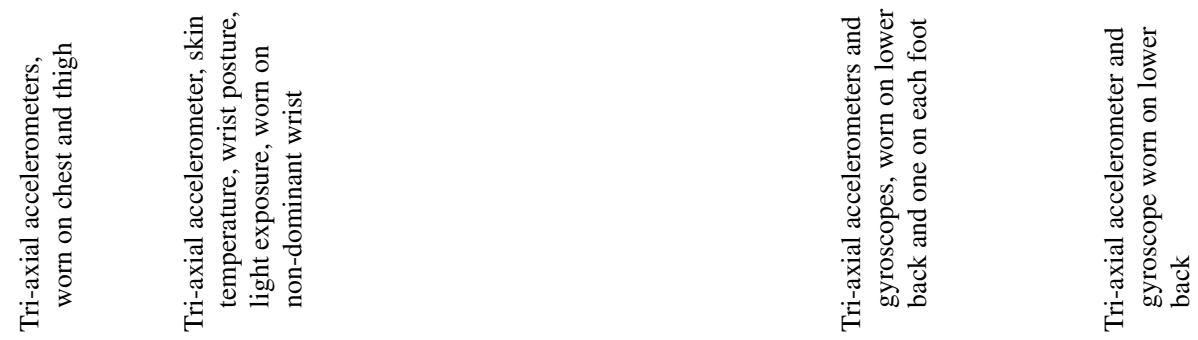

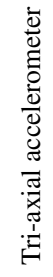
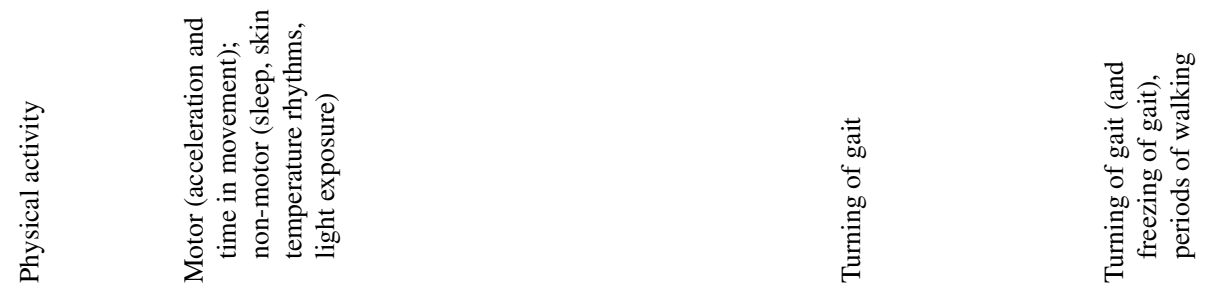


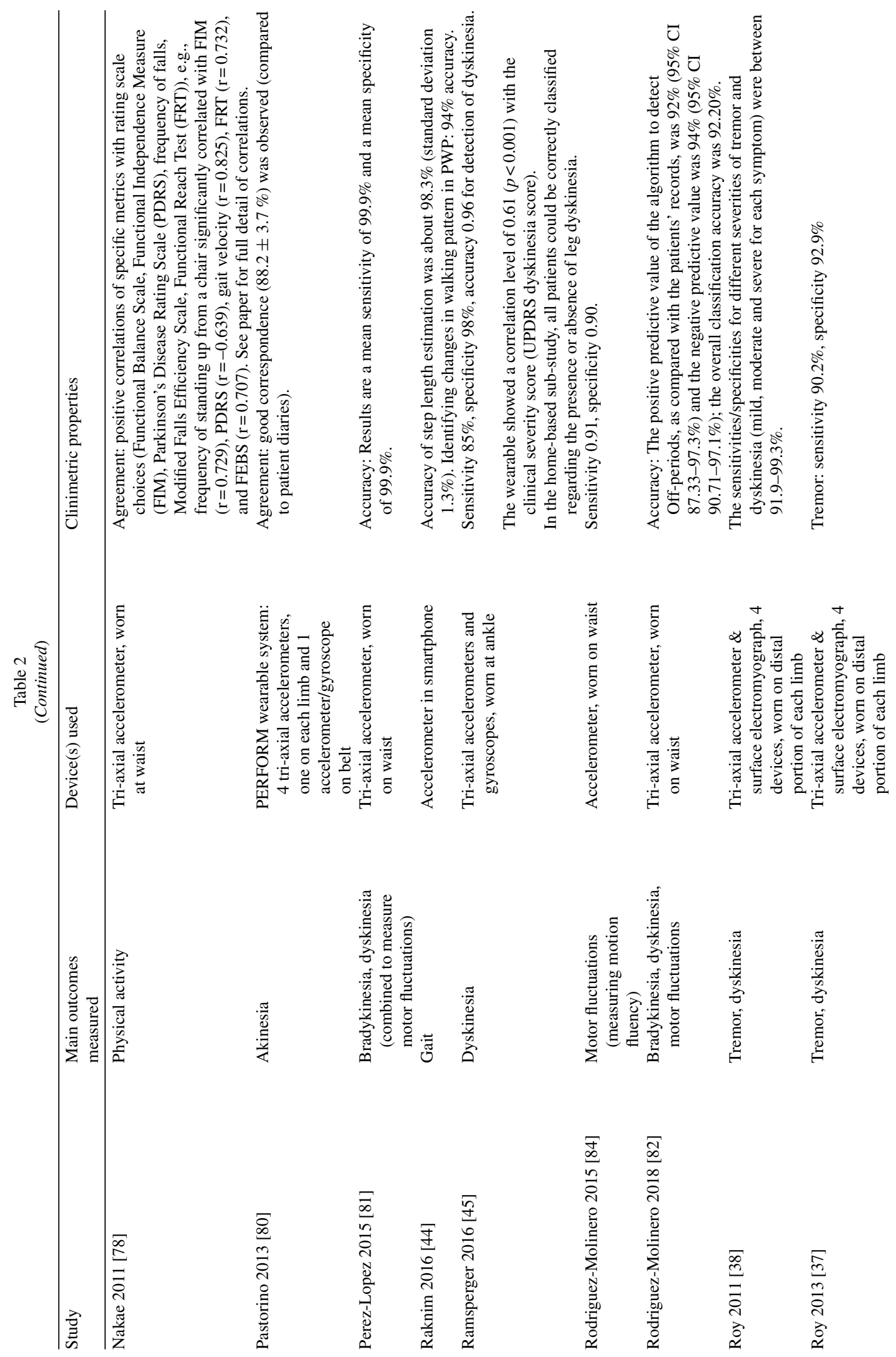



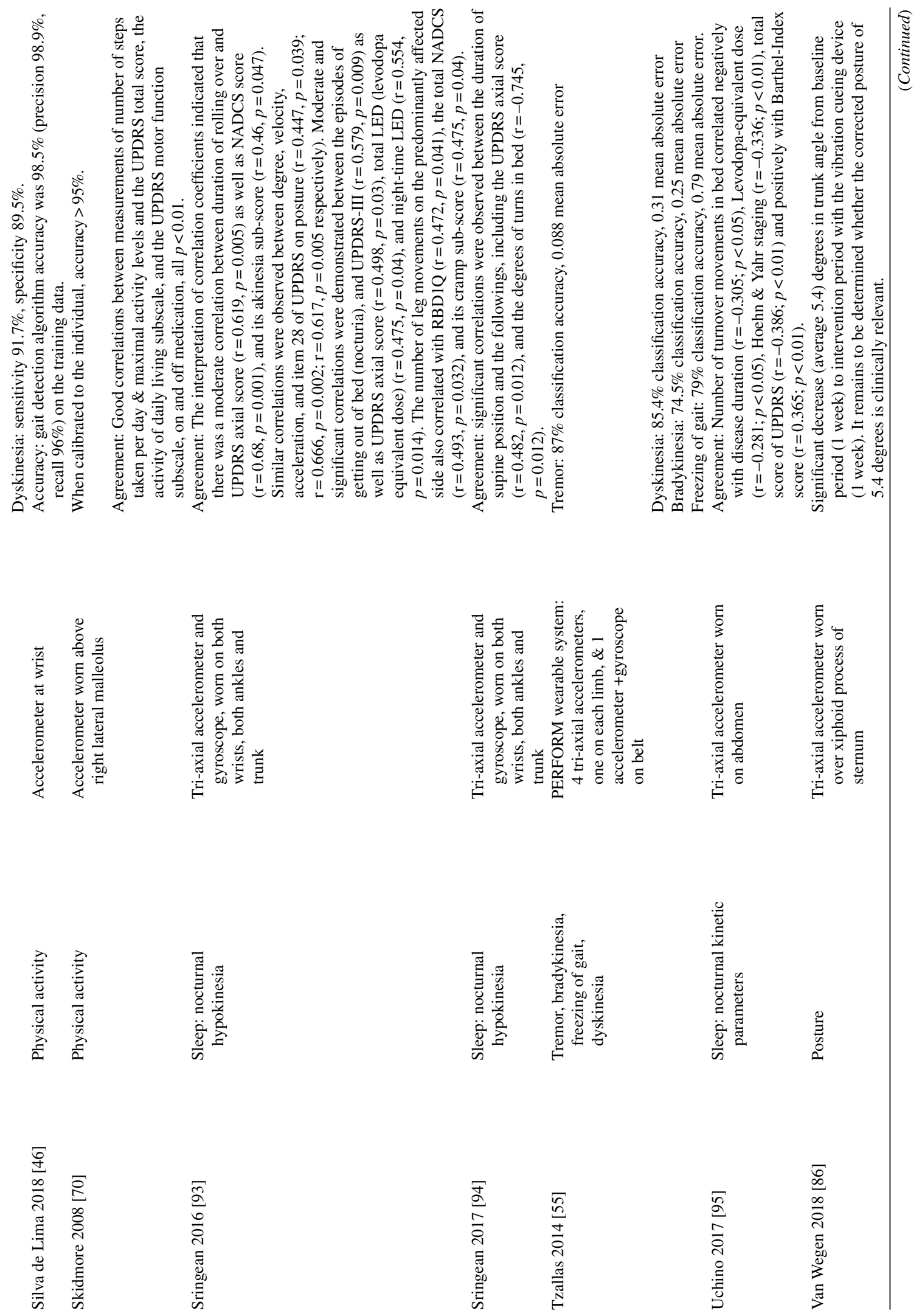


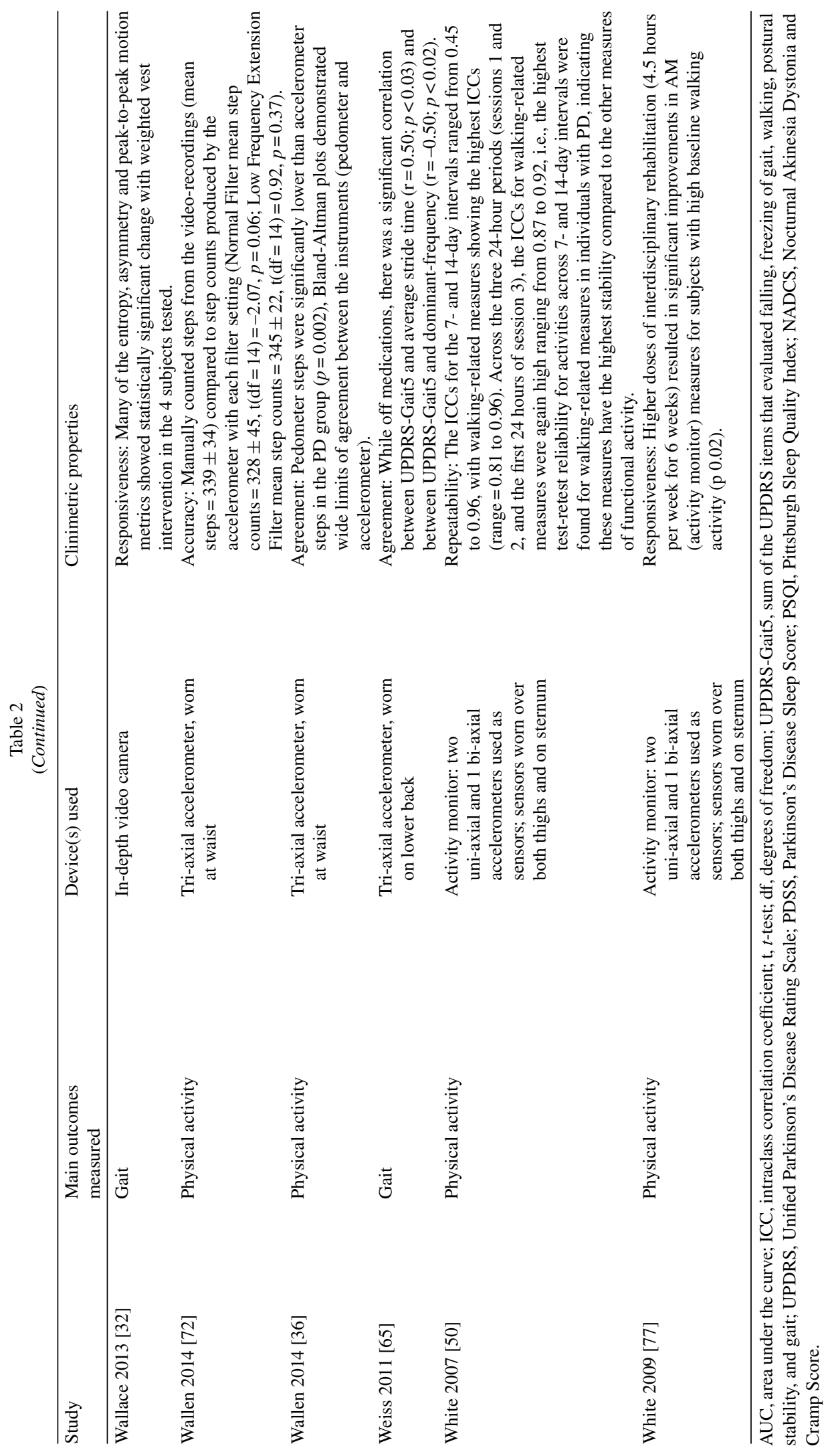


these studies employed wearable devices, with single devices being used in four studies [41, 56, 66, 67], and multiple devices employed in the other papers [37-40, 52, 54, 55, 68, 69]. All researchers measuring tremor used accelerometers within the wearable devices, with five additionally using gyroscopes [52, 54-56, 69] and four studies using surface electromyographic sensors [37-40]. Clinimetric properties were mentioned in nine studies. These clinimetric properties are shown in Table 2; they comprise of statistics of accuracy and/or sensitivity/specificity, with all outcomes documented at $>90 \%$ apart from the classification accuracy for tremor of $87 \%$ produced by the PERFORM system (described in two papers [52, 55]). Validation efforts for the tremor metric were described by three groups. Cole et al. [40] validated algorithm development through video annotation of the PD metrics (tremor and dyskinesia) and used this validation to inform subsequent work [39]; Sama et al. [56] also used videotape comparison to validate. Silva de Lima et al. [41] described validation data from previous work using direct clinician-measured PD symptom severity [67].

\section{Physical activity}

Of the studies included in the review, 17 measured the metric of physical activity. 13 of these papers described the use of single wearable devices $[29,36,41,46,49,67,70-76]$, whereas four used multiple wearables $[35,50,77,78]$. Each study used accelerometry only to measure physical activity except for Cereda et al, who used accelerometry, body temperature, skin conductivity and the sleep-wake rhythm to measure total daily energy expenditures, physical activity, number of steps and metabolic rate of their participants [74] in the context of investigating the impact of a low protein diet on physical activity and energy expenditure. Clinimetric properties were evaluated in 12 papers, with results detailed in Table 2. Accuracy of the technology was evaluated by Silva de Lima et al. [46], Skidmore et al. [70] and Wallen et al. [72] with $>95 \%$ accuracy found in the former two studies. Agreement with a number of different tools (including UPDRS II \& III, Functional Independence Scale, Functional Balance Measure) was investigated by 5 papers $[29,36,49,70,78]$ with varying results. These included the absence of agreement being noted, for example between accelerometry measuring physical activity and the UPDRS motor subscale (III) [29, 49]. Repeatability was looked at by White et al.
[50] and Hale et al. [75] with test-retest evaluation which demonstrated good intra-class correlation coefficients in both papers. Responsiveness was evaluated by three studies: Lim et al. [35] looked at cueing training (significant improvements seen which declined at further follow-up), Lloret et al. [76] performed a levodopa challenge in the laboratory setting (no responsiveness of technology-assisted outcomes) and White et al. [77] noted the responsiveness of their accelerometry data to inter-disciplinary rehabilitation (improvements seen in group with high baseline walking activity). Validation work was referred to in support of seven papers' findings. Silva de Lima et al. looked at gait detection and activity level and used clinician-observed structured assessments to produce a labelled training dataset [67] with which to inform their subsequent work included in this review [41, 46]. White et al. [50, 77] referred to a previous study using videotape to validate activity monitoring [79] and Lim et al. [35] also referred to this study's validity testing in their paper. Wallen et al. [72, 73] used videotape to record a structured 3-minute walk in 15 people with PD to aid validation of their technologyassisted outcome measures [72]. Cavanaugh et al. compared the monitor's step counts identified via a flashing indicator light with visual observation [49].

\section{Bradykinesia}

Often combined with other motor outcomes such as dyskinesia or gait, eight studies investigated the ability of technology to measure bradykinesia/akinesia in their participants $[42,52,54-56$, 80-82]. All the research groups used wearable devices to measure bradykinesia/akinesia: four used single devices whereas four used multiple wearable devices. All of the devices employed to measure bradykinesia/akinesia contained accelerometers, with gyroscopes also in four devices [52, $54,55,80]$ and a gyroscope/magnetometer within one [56]. Validation was attempted through the use of videotape $[55,56]$, comparison with the UPDRS [42, 52], the use of telephone calls from researchers and comparison with participant study diaries [82]. Clinimetric properties were evaluated in six studies, and included measurements of accuracy [52, 55, 81, 82] and agreement (Pastorino et al. [80] documented good correspondence of $88.2 \%$ between technological outcomes and participant diaries). Responsiveness to dose adjustments of levodopa/carbidopa was assessed in a study by Johansson et al. [42], with the UPDRS motor scores 
changing significantly $(\mathrm{P}<0.05)$ but the wearable device's summary scores (bradykinesia \& dyskinesia) showing no significant change following dose adjustments of levodopa/carbidopa. More detail about clinimetric properties is in Table 2.

\section{Dyskinesia and motor fluctuations}

Motor fluctuations specifically were evaluated as a stand-alone outcome measure by two studies [83, 84], and they were evaluated alongside the dyskinesia outcome measure in three papers [81, 82, 85]. Dyskinesia was measured by technologies in 11 further papers included in this review [37-40, 42, 45, $52,54-56,68]$. Wearable devices were used in all studies which evaluated dyskinesia and/or motor fluctuations, with seven using single wearable devices. Sama et al. [56], Rodriguez-Molinero et al. [82, 84] and Perez-Lopez et al. [81] used devices located at the waist or on the belt, Johansson et al. [42] and Bayes et al. [83] used a device at the wrist and Ramsperger et al. [45] used an ankle-worn device. Accelerometers were ubiquitously employed; they were used in some studies without other sensing technology and in other papers alongside gyroscopes [45, 52, 54-56], magnetometers [56] and surface electromyographs [37-40]. Validation of dyskinesia outcome measurements had been documented in eight papers, with various comparators used as ground truth to aid validation, including videotape recordings [39, 40, 55, 56, 84], direct clinician evaluation/observation [42, 83, 84], and participant diaries plus telephone calls from a researcher [82]. The clinimetric properties of the technologies under evaluation, where discovered, are detailed more fully in Table 2. The authors of this review were able to find some clinimetric evaluation in 14 of the papers: accuracy/sensitivity/specificity were the most frequently mentioned properties [37-40, 45, 52, 55, 68, 81-85]; agreement with the UPDRS dyskinesia score [45] and participant diaries [85] was also noted by specific studies; the responsiveness results from Johansson et al. [42] are noted in the sub-section above (bradykinesia).

\section{Posture}

A single study looked exclusively at posture in the context of investigating whether posture detection and subsequent vibrotactile trunk ankle feedback could improve posture of participants [86]. The single tri-axial accelerometer-containing device located over the xiphoid process of the sternum was used both to collect movement data and provide feedback to the participant. Validation testing was not immediately evident, however responsiveness of the device's measurement of posture as a result of the intervention showed a significant decrease (average 5.4 degrees) in trunk angle from baseline period to intervention period with the vibration cueing.

Falls

Godfrey et al. [62] looked at the identification of falls in the free-living environment using a single wearable tri-axial accelerometer located on the back. The ground truth was provided by the participant diary recording the single fall which occurred during the study; this fall was correctly identified by the wearable device and the pre-fall event was correctly segmented by the algorithm, however 38 false positives (falls) were also detected by the algorithm. Stack et al. [47] used wearable devices (tri-axial accelerometers and gyroscopes worn on each wrist, each ankle and lower back), along with the non-wearable Kinect camera, to evaluate movement around the house in order to identify high risk of falling in their participants.

\section{Typing}

The analysis of the typing patterns to investigate motor impairments in PD was conducted by three studies. Adams et al. [87] used keystroke timing information analysed by machine learning classification models to successfully discriminate between earlyPD subjects and controls with a $96 \%$ sensitivity, a $97 \%$ specificity and an area under the curve (AUC) of 0.98. Arroyo-Gallego et al. [30] employed a 'NeuroQWERTY' algorithm and this had a sensitivity of $73 \%$ and specificity of $69 \%$ in home-based testing when compared to a controlled typing test in this environment. There was significant moderate correlation with the UPDRS III with correlation coefficients of 0.50 in clinic and 0.34 at home. Prior validation work of this algorithm, comparing typing outcomes of people with PD vs controls and comparing with the UPDRS III, had been conducted in a laboratory setting [88]. A third study by Vega [48] employed all of the sensors and interfaces within a smartphone, complemented by ambient, spatial and other web data sources, to analyse various behaviours including typing patterns, social and phone usage patterns and motor activities [48]. They propose that these met- 
rics could signify hand movement performance and patterns; however the study detailed early pilot work at this stage which had not been clinimetrically tested or validated.

\section{Sleep}

Sleep had been measured in 11 of the studies included in this systematic review [31, 33, 41, 67, 89-95]. Wearable devices were used to measure sleep outcomes in all of these studies. Single devices were used in eight of the 11 studies, worn on the trunk, wrist [41, 67, 89, 91], lower limb [92] and abdomen [95]. The location of the technology depended on what aspect of sleep was being evaluated, for example Prudon et al. using lower limb placement to measure periodic limb movements of sleep [92]. Multiple device platforms were described in three of the studies [90, 93, 94]; of note, Gros et al. [90] were interested in quantifying apnoea, hypopnoea, oxygen desaturation and pulse rate using two respiratory inductance plethysmography belts, a nasal pressure cannula and a pulse oximeter. Accelerometers were used in all of the wearable devices, accompanied by gyroscopes in four papers (all using the 'NIGHTRecorder' device to measure nocturnal hypokinesia) [31, 33, 93, 94]. Validation had been attempted, if documented, in five studies, with the use of sleep diaries [31, 33, 93, 94], polysomnography [92] and night-time video recordings [94] to provide ground truth. Clinimetric properties are detailed in Table 2; however, there was a range of information about accuracy and agreement with clinical rating scales and questionnaires. Two studies looked at responsiveness of the technology-assisted outcome measures, one in the context of Rotigotine treatment [33] (where the Rotigotine was shown by the technology to effect a significant difference in change from baseline score in the number of turns in bed $(p=0.001)$, and degree of axial turn $(p=0.042))$ and the other in response to Levodopa/Carbidopa Intestinal Gel treatment [89]. In this particular study by Madrid-Navarro et al, the same patient was recorded three times throughout the course of the study. She was a 61-year-old woman with advanced PD who was monitored before, 1 week after, and 6 months after starting intra-jejunal infusion of Levodopa-Carbidopa Intestinal Gel by a single tri-axial accelerometer with additional skin temperature, wrist posture and light exposure measurements worn on the non-dominant wrist. The A/T ratio (the ratio of acceleration during the daytime over time in movement during sleep) increased from 0.15 to 0.75 and $1.99,1$ week and 6 months after the onset of treatment, respectively.

\section{Activities of daily living}

Vega [48], described above in context of evaluating typing, used the sensors and interfaces within a smartphone to identify latent behavioural variables which he could use to measure outcomes in PD. These variables included daily living activities such as phone usage patterns, social patterns and indoors routine. Given the early nature of this pilot work there was no validation/clinimetric testing documented. The metric of 'lifespace', a phrase given to the number of trips outside a home of $>500$ metres, the length of distance travelled and approximate location to which travelled, was measured by Liddle et al. [43] using a single Global Positioning System within an Android smartphone. No validation or clinimetric testing was mentioned.

\section{DISCUSSION}

This systematic review is, to our best knowledge, the first to evaluate the existing evidence around the use of both wearable and non-wearable technology which passively evaluates unstructured activities (free-living) in the home or home-like environment in order to generate outcome measures in PD. It complements work looking at wearable technologies specifically [96-99], outcome measures in PD using technology in any testing environment (technologies are largely tested in a laboratory environment) [11, $14,100]$ and more specific reviews looking at individual symptom assessment using sensors [101, 102]. Additionally, for those interested, this review provides some thoughts on future avenues to improve and expand this approach to PD outcome measure testing at home.

\section{Types of studies}

This review found that of the 65 studies selected for data extraction, the study designs were mostly observational which is perhaps intuitive given the passive nature of free-living monitoring in which the authors were interested. The studies were set in the participants' real home setting with only infrequent exceptions [37-40]. Home-based testing may be beneficial in PD partly to cater for those patients who are limited geographically or practically from attending frequent clinic assessments [103], partly to save costs 
[25] and importantly to achieve ecological validity in the assessment of PD symptoms which are poorly captured in 'snap-shot' reviews in a laboratory or clinic environment [8].

The sample sizes used ranged widely from fewer than 10 to several hundred participants. The ideal numbers of participants to include in such studies depend on the intent of the researchers: whilst 10-12 participants may be enough to create a training dataset [104], smaller studies cannot sufficiently reflect the heterogeneous spectrum of clinical PD [105], therefore larger studies will ultimately be needed in order to ensure that the technologies are generalizable. The large sample sizes displayed by a number of papers $[35,41,46,52,61,63,67,92]$ are good indicators of the encouraging potential of technology to be scalable for use in clinical care and in trials but the data required to guide power calculations for future investigations employing these types of outcome measures remains yet to be determined.

The long duration of 10 studies of between 2 weeks and 1 year is encouraging as it demonstrates the potential to employ technology for periods of time sufficient to capture rare events such as falls [106], which can be difficult to recreate for evaluation in a laboratory environment. Interestingly, we found technology-assisted outcome measures being used in an episodic way by some groups [35, 49, 50] instead of continuously. These 'snap-shot' measurements potentially lend themselves more towards adjunctive outcome measurements in clinical trial contacts or for use when a patient with PD visits the outpatient clinic.

\section{Technologies used}

The most frequently investigated sensors for the monitoring of PD symptoms were inertial measurement units within wearable devices and/or smartphones. This is possibly because these devices are commercially available, low cost, easy to use, small and are very frequently used anyway by the general population, so are likely to be acceptable. The development of the Internet of Things has also made it easier to transfer large amounts of data from wearables to electronic storage without needing to plug the wearables in using extra hardware. The use of non-wearable devices within our included studies was limited to depth video cameras and computer keyboards.

We found a significant number of studies utilising multiple sensors, as opposed to a single sensor, to measure outcomes in PD. The term 'multiple sensors' could include multiple wearable sensors, a combination of wearable and non-wearable devices, or multiple non-wearable sensors. There is currently no consensus on the optimum number of sensors to use to measure outcomes in PD; the balance is between the system being unobtrusive and acceptable enough for deployment into a participant's life for prolonged periods of time versus the need to avoid loss of potentially relevant information through using too few sensors. When considering acceptability of technology-observed measures in PD, the authors are not aware of any overwhelmingly negative reports; however publication bias favouring publication of positive acceptability outcomes of technology is a possibility in this circumstance. Due to the fact that wearable devices are not completely unobtrusive and will always carry some physical burden when compared to non-wearable devices, it is possible that alternative approaches will (continue to) find their way into research and clinical practice. For example, the concept of a 'smart home' (with inbuilt unobtrusive sensors) added to wearables, smartphones passively monitoring and the Internet of Things could provide researchers with a menu of valuable tools.

\section{What is being measured?}

With respect to motor outcomes, we found that the devices are being used to measure outcomes such as gait, physical activity levels, bradykinesia or akinesia, dyskinesia and tremor, but there were no papers evaluating rigidity and few which were measuring falls or posture. Additionally, technology was used to measure motor fluctuations in five of the included papers [81-85] with some encouraging results in terms of accuracy (see Table 2). Motor fluctuations are a relevant burden for patients [107] but are arguably inadequately quantified by the gold-standard clinical rating scales frequently used in clinical trials and in clinical practice. This review demonstrates that this metric, and other motor outcomes, are starting to be measured in a continuous and unobtrusive way in the home setting although much further work in this area is required.

Considering non-motor symptoms, sleep is evaluated in 11 studies, predominantly using wearable devices. This patient-relevant [108] 'outcome' in PD is very complicated with various sleep diagnoses being more common in the PD population (e.g., REM sleep behaviour disorder, restless legs syndrome, insomnia) [109]. Other non-motor outcomes 
remain largely unmeasured in the home environment. This is important, since symptoms such as depression, cognitive dysfunction and autonomic function are known to impact on health-related quality of life and wellbeing [22, 71]. In one survey, almost half the respondents felt that non-motor symptoms had a greater impact on quality of life than motor symptoms [110]. The methodology of how to measure non-motor symptoms such as fatigue or pain using technology may appear challenging, however there is potentially interesting work linking wearable accelerometer data used to measure bradykinesia with constipation outcomes [111]. This provides the hope that technology can be used in conjunction with other tools to measure these symptoms in PD at home, the under-measurement of which is highlighted by this review.

Activities of daily living were quantified to an extent in two papers, although one described early pilot work so far only [48] and the other investigated a metric of 'lifespace' which involved trips from the home to other places and not activities within the home itself [43]. It has been shown that ADLs and the ability to perform them have a significant impact on health-related quality of life [112]. Currently, ADLs are often evaluated through clinician questions or in the MDS-UPDRS part II, which is performed normally in an outpatient setting on regular occasions, leaving weeks/months between assessments. Researchers have argued that the best location to assess everyday functional abilities is in a participant's own (home) environment [113]. Our review highlights that the measurement of free-living ADLs at home is an avenue for future work and is relatively unexplored.

\section{Validation}

A home-based sensor system, continuously monitoring the symptoms of PD, could be a pathway towards personalising medical treatments and reducing hospital visits both in clinical care and in clinical trials [96]. However, the validation of such a system in a participant's home, remote from researchers who could annotate the activities and potentially without a video camera system to provide ground truth, presents challenges as described below.

There are various aspects to consider when discussing the validation of technology-assisted outcome measures in PD. A focus of validation can be on the technical aspects of the study, for example to validate whether an algorithm operating on the data gathered from sensor(s) is meeting a defined set of requirements. This is distinct from clinical validation where validation is a check that the technologyderived outcome is an accurate representation of the symptom/behaviour/body function being measured. Clinical validation can be achieved in a number of ways, often including the use of study participant diaries, direct observation by a researcher and/or annotation of video data to give a ground truth. A good quality validation dataset would depend on the symptom or activity under evaluation; generally, due to the complex and heterogeneous nature of the condition, having a dataset which incorporates many individuals would increase the generalisability of the results of validation [104]. A ground truth involving frequent annotations [114] from expert clinical raters (with which to compare to sensor data) should also improve the ability to accurately validate the technology outcomes.

This review found that 35 studies mentioned validation attempts of their technologies in PD using various methods: videotape analysis was used to validate technologies described by 19 papers $[39,50$, 51, 53, 55-61, 67, 72, 73, 77, 84, 85, 94], direct clinician observation in six [41, 46, 49, 58, 65, 83], participant diaries in seven $[31,33,62,82,85,93$, 94], comparison with the MDS-UPDRS or another clinical rating scale was used in three studies [42, $65,80]$, an instrumented walkway in three $[61,63$, $64]$, motion analysis in three $[53,59,60]$, comparison to other wearable devices or device filter settings in three $[36,44,72]$, telephone calls from a researcher in one [82], polysomnography in one paper [90] and sleep respiratory home monitoring (assessing snoring, nasal airflow, oxygen saturation, body position, and respiratory and abdominal wall movements) in another [92].

In terms of location of validation efforts: participant diaries, telephone calls from researchers and comparison with other wearable devices or device filter settings could all be collected in the home setting. The single paper using polysomnography performed this validation in the laboratory [90], but an attenuated sleep monitoring system was deployed to the participants' home in another paper [92]. As far as the authors of this review could ascertain, the validation efforts using video recordings, motion analysis, instrumented walkways and direct clinician observations/interactions were all conducted in a laboratory setting (either in the paper itself or in previous work) prior to the deployment of the technology to the naturalistic setting. 
The transfer of validated technology-assisted outcomes from laboratory to home settings is not without issues. These include the different contexts (environment and task) which could change movement outcomes and algorithm accuracies; the ability to prevent hardware damage/accidents for example is more limited; external factors such as mood and medication could introduce variability. Of interest, Fisher et al. [85] used an Artificial Neural Network to identify disease states (dyskinesia, ON/OFF state) first in the laboratory and then unsupervised at home, and compared to diaries and clinician rating of disease state. In the laboratory, the specificity for dyskinesia detection was $99 \%$, and in the home environment the specificity was also $93 \%$, but the sensitivity was low at $38 \%$ with suboptimal sensitivity for on/off state. This demonstrates that this technology which was validated in the laboratory was not ready for deployment to the home; this could potentially be the case for many such technologies if tested in a similar way.

Validation in the home environment itself, particularly when measuring unstructured/free-living activities, can be challenging: the presence of cameras or an observer could influence the behaviour of a study participant [10]; also the heterogeneity of the layout of peoples' homes could make camera placement to achieve reliable ground truth difficult. The use of participant diaries to validate the technology, often with a diary entry frequency of every 30 minutes, arguably would also disrupt the free living being evaluated by technology and are also limited by self-reporting biases, cognitive impairments limiting recording accuracy and motor impairments which make symptom recording challenging [115]. The limitations of the MDS-UPDRS have already been discussed and lead to this clinical rating scale not being particularly helpful for most technology validation needs. As it currently stands, testing the technology against itself using test-retest repeatability and responsiveness, for example, may be the best way of validating results.

\section{Clinimetric properties}

The diverse study designs, methods, sample sizes and statistical analyses of the papers included in this review mean that clinimetric properties could not be compared to each other. Twelve studies did not include detail about clinimetric properties tested to the best of the authors' knowledge, however all other studies tested one, or a combination of, clinimetric properties including accuracy/sensitivity/specificity, agreement, repeatability and responsiveness. The discussion surrounding how successful each paper was in assessing clinimetric properties is beyond the scope of this paper as each study was conducted in a different manner with diverse patient populations, testing procedures, technologies and algorithms.

\section{Limitations}

This systematic review has limitations. One author undertook most of the abstract and full text screening work (C.M.). However, $10 \%$ of these abstracts and full texts were cross-checked and screened by another author (M.R.) for accuracy. There were a number of papers for which full-texts could not be obtained from an initial university electronic library database search. In these instances the authors used further search and direct enquiry within a university library service for named manuscripts and also employed the use of a mainstream (academic) search engine; however if the full text still remained unavailable these studies were excluded and this exclusion could have impacted upon our study results. These excluded papers are listed in the Supplementary material (Table 2). Another limitation is the potential for publication bias and the potential that small positive studies were more likely to be published than those with negative results. The time frame for literature search from 2000 was a bridge between two excellent reviews detailing the previous 10 years' literature on the topic $[14,96]$ and examples of other authors who conducted open-ended searches [11]. Relevant papers from pre-2000 may have been omitted, however one previous systematic review documented more than $50 \%$ of their studies included had been published in the preceding 3 years to 2016 [96], so the likelihood of substantial numbers of studies having been missed by our search strategy is low.

\section{Future directions}

We found that most studies had investigated the use of technology-assisted outcome measures to look at motor features of PD or sleep. There is a need for a focus to be directed towards non-motor symptoms and ADLs, impairment of which significantly impacts upon the health-related quality of life of people with PD [112]. Since there are so many separate groups working across the world looking at similar technological sensors to measure outcomes in PD, it is worth noting that collaborative efforts includ- 
ing dataset sharing/cross-validation approaches will be vital to ensure that groups avoid replicating work that is already done and instead can move this exciting field forwards. Advances in IoT technology have brought with them privacy and data security concerns and it is important that these are addressed robustly to avoid data breaches and loss of confidence in what promises to be a valuable way of measuring PD.

Additionally, a vital issue is whether regulatory bodies (for example the Federal Drugs Agency or European Medicines Agency) recognise and approve the measurement systems in order to build for their futures as widely-accessed tools in clinical care and clinical trials. Most tools are not yet approved by the FDA/EMA. A further point is whether these devices have CE (Conformité Européene) marking to provide some assurance that they comply with the essential requirements of the relevant European health, safety and environmental product legislation, including enforcing legal obligations regarding data. The latter is particularly important and brings legal obligations regarding data privacy and ownership. Moreover, in order for the technology to be recommended by NICE (National Institute of Clinical Excellence) in the United Kingdom (UK) for example, enough clinical and economic evidence needs to be gathered that the device(s) will be beneficial to health and good value for money for the UK's National Health Service [116].

There are constructive initiatives aiming to move this field forward (with industry, academics and others) in a collaborative and appropriate way towards the adoption of health technologies to measure outcomes in PD, such as the Movement Disorders Society Taskforce on Technology's recent 'roadmap' [19] and Mobilise D [117].

\section{Conclusion}

A number of groups are using technological devices to produce outcome measures in PD through the evaluation of free-living activities in the home or home-like environment. This will continue to be important as we learn how sensors can best be used to unobtrusively and accurately measure clinically and functionally important aspects of this common and debilitating disease. This review provides an overview of the current evidence in free-living homebased sensor testing in PD. It will be vital to continue to keep up-to-date with new advancements in this rapidly evolving scientific field.

\section{ACKNOWLEDGMENTS}

This work is supported by the Elizabeth Blackwell Institute for Health Research, University of Bristol and the Wellcome Trust Institutional Strategic Support Fund, grant code: 204813/Z/16/Z.

Dr Jonathan de Pass and Mrs Georgina de Pass made a charitable donation to the University of Bristol (of which Jonathan is a graduate) through the Development and Alumni Relations Office to support research into $\mathrm{PD}$. The funding pays for the salary of C.M., the PhD student and Clinical Research Fellow, and she reports to the donors on her progress but they do not have any influence on the direction of her research work.

\section{CONFLICT OF INTEREST}

The authors have no conflict of interest to report.

\section{SUPPLEMENTARY MATERIAL}

The supplementary material is available in the electronic version of this article: https://dx.doi.org/ 10.3233/JPD-191781.

\section{REFERENCES}

[1] GBD 2016 Parkinson's Disease Collaborators (2018) Global, regional, and national burden of Parkinson's disease, 1990-2016: A systematic analysis for the Global Burden of Disease Study 2016. Lancet Neurol 17, 939-953.

[2] Jankovic J (2008) Parkinson's disease: Clinical features and diagnosis. J Neurol Neurosurg Psychiatry 79, 368376.

[3] Fineberg NA, Haddad PM, Carpenter L, Gannon B, Sharpe R, Young AH, Joyce E, Rowe J, Wellsted D, Nutt DJ, Sahakian BJ (2013) The size, burden and cost of disorders of the brain in the UK. J Psychopharmacol 27, 761-770.

[4] Goetz CG, Fahn S, Martinez-Martin P, Poewe W, Sampaio C, Stebbins GT, Stern MB, Tilley BC, Dodel R, Dubois B, Holloway R, Jankovic J, Kulisevsky J, Lang AE, Lees A, Leurgans S, LeWitt PA, Nyenhuis D, Olanow CW, Rascol O, Schrag A, Teresi JA, Van Hilten JJ, LaPelle N (2007) Movement Disorder Society-sponsored revision of the Unified Parkinson's Disease Rating Scale (MDSUPDRS): Process, format, and clinimetric testing plan. Mov Disord 22, 41-47.

[5] Goetz CG, Tilley BC, Shaftman SR, Stebbins GT, Fahn S, Martinez-Martin P, Poewe W, Sampaio C, Stern MB, Dodel R, Dubois B, Holloway R, Jankovic J, Kulisevsky J, Lang AE, Lees A, Leurgans S, LeWitt PA, Nyenhuis D, Olanow CW, Rascol O, Schrag A, Teresi JA, van Hilten JJ, LaPelle N (2008) Movement Disorder Society-sponsored revision of the Unified Parkinson's Disease Rating Scale (MDS-UPDRS): Scale presentation and clinimetric testing results. Mov Disord 23, 2129-2170. 
[6] Post B, Merkus MP, de Bie RMA, de Haan RJ, Speelman JD (2005) Unified Parkinson's disease rating scale motor examination: Are ratings of nurses, residents in neurology, and movement disorders specialists interchangeable? Mov Disord 20, 1577-84.

[7] Mcghee DJM, Ritchie CW, Zajicek JP, Counsell CE (2016) A review of clinical trial designs used to detect a diseasemodifying effect of drug therapy in Alzheimer's disease and Parkinson's disease. BMC Neurol 16, 92.

[8] Regnault A, Boroojerdi B, Meunier J, Bani M, Morel T, Cano S (2019) Does the MDS-UPDRS provide the precision to assess progression in early Parkinson's disease? Learnings from the Parkinson's progression marker initiative cohort. J Neurol 266, 1927-1936.

[9] Shulman LM, Gruber-Baldini AL, Anderson KE, Fishman PS, Reich SG, Weiner WJ (2010) The clinically important difference on the Unified Parkinson's Disease Rating Scale. Arch Neurol 67, 64-70.

[10] Robles-García V, Corral-Bergantiños Y, Espinosa N, Jácome MA, García-Sancho C, Cudeiro J, Arias P (2015) Spatiotemporal gait patterns during overt and covert evaluation in patients with Parkinson's disease and healthy subjects: Is there a Hawthorne effect? J Appl Biomech 31, 189-94.

[11] Godinho C, Domingos J, Cunha G, Santos AT, Fernandes RM, Abreu D, Gonçalves N, Matthews H, Isaacs T, Duffen J, Al-Jawad A, Larsen F, Serrano A, Weber P, Thoms A, Sollinger S, Graessner H, Maetzler W, Ferreira JJ (2016) A systematic review of the characteristics and validity of monitoring technologies to assess Parkinson's disease. $J$ Neuroeng Rehabil 13, 24.

[12] Gao J, Tian F, Fan J, Wang D, Fan X, Zhu Y, Ma S, Huang J, Wang H (2018) Implicit detection of motor impairment in Parkinson's disease from everyday smartphone interactions. In Extended Abstracts of the 2018 CHI Conference on Human Factors in Computing Systems - CHI' 18 ACM Press, New York, New York, USA, pp. 1-6.

[13] Aghanavesi S, Nyholm D, Senek M, Bergquist F, Memedi M (2017) A smartphone-based system to quantify dexterity in Parkinson's disease patients. Informatics Med Unlocked 9, 11-17.

[14] Sánchez-Ferro Á, Elshehabi M, Godinho C, Salkovic D, Hobert MA, Domingos J, van Uem JMT, Ferreira JJ, Maetzler W (2016) New methods for the assessment of Parkinson's disease (2005 to 2015): A systematic review. Mov Disord 31, 1283-1292.

[15] Cook DJ, Schmitter-Edgecombe M, Dawadi P (2015) Analyzing activity behavior and movement in a naturalistic environment using smart home techniques. IEEE J Biomed Heal informatics 19, 1882-1892.

[16] Memedi M, Tshering G, Fogelberg M, Jusufi I, Kolkowska E, Klein G (2018) An interface for IoT: Feeding back health-related data to Parkinson's disease patients. J Sens Actuator Networks 7, 14.

[17] Lang AE, Melamed E, Poewe W, Rascol O (2013) Trial designs used to study neuroprotective therapy in Parkinson's disease. Mov Disord 28, 86-95.

[18] Isaacson SH, Boroojerdi B, Waln O, McGraw M, Kreitzman DL, Klos K, Revilla FJ, Heldman D, Phillips M, Terricabras D, Markowitz M, Woltering F, Carson S, Truong D (2019) Effect of using a wearable device on clinical decision-making and motor symptoms in patients with Parkinson's disease starting transdermal rotigotine patch: A pilot study. Parkinsonism Relat Disord 64, 132-137.
[19] Espay AJ, Hausdorff JM, Sánchez-Ferro Á, Klucken J, Merola A, Bonato P, Paul SS, Horak FB, Vizcarra JA, Mestre TA, Reilmann R, Nieuwboer A, Dorsey ER, Rochester L, Bloem BR, Maetzler W, Movement Disorder Society Task Force on Technology (2019) A roadmap for implementation of patient-centered digital outcome measures in Parkinson's disease obtained using mobile health technologies. Mov Disord 34, 657-663.

[20] Duncan RP, Earhart GM (2011) Measuring participation in individuals with Parkinson disease: Relationships with disease severity, quality of life, and mobility. Disabil Rehabil 33, 1440-1446.

[21] Silva de Lima AL, Smits T, Darweesh SKL, Valenti G, Milosevic M, Pij1 M, Baldus H, de Vries NM, Meinders MJ, Bloem BR (2019) Home-based monitoring of falls using wearable sensors in Parkinson's disease. Mov Disord 35, 109-115.

[22] Van Uem JMT, Isaacs T, Lewin A, Bresolin E, Salkovic D, Espay AJ, Matthews H, Maetzler W (2016) A viewpoint on wearable technology-enabled measurement of wellbeing and health-related quality of life in Parkinson's disease. $J$ Parkinsons Dis 6, 279-287.

[23] Schlachetzki JCM, Barth J, Marxreiter F, Gossler J, Kohl Z, Reinfelder S, Gassner H, Aminian K, Eskofier BM, Winkler J, Klucken J (2017) Wearable sensors objectively measure gait parameters in Parkinson's disease. PLoS One 12, e0183989.

[24] Zhan A, Little MA, Harris DA, Abiola SO, Dorsey ER, Saria S, Terzis A (2016) High frequency remote monitoring of Parkinson's disease via smartphone: Platform overview and medication response detection. arXiv:1601.00960 [cs.CY].

[25] Cubo E, Mariscal N, Solano B, Becerra V, Armesto D, Calvo S, Arribas J, Seco J, Martinez A, Zorrilla L, Heldman D (2017) Prospective study on cost-effectiveness of home-based motor assessment in Parkinson's disease. $J$ Telemed Telecare 23, 328-338.

[26] Toosizadeh N, Mohler J, Lei H, Parvaneh S, Sherman S, Najafi B (2015) Motor performance assessment in Parkinson's disease: Association between objective inclinic, objective in-home, and subjective/semi-objective measures. PLoS One 10, e0124763.

[27] Morgan C, Rolinski M, Jones B, Whone AL (2019) Protocol of systematic review of technology use to measure free-living outcomes in Parkinson's disease in a home-like environment - University of Bristol. https://researchinformation.bris.ac.uk/1-4.

[28] Covidence systematic review software. Veritas Health Innovation, Melbourne, Australia. Available at www.covidence.org.

[29] Cai G, Huang Y, Luo S, Lin Z, Dai H, Ye Q (2017) Continuous quantitative monitoring of physical activity in Parkinson's disease patients by using wearable devices: A case-control study. Neurol Sci 38, 1657-1663.

[30] Arroyo-Gallego T, Ledesma-Carbayo MJ, Butterworth I, Matarazzo M, Montero-Escribano P, Puertas-Martín V, Gray ML, Giancardo L, Sánchez-Ferro Á (2018) Detecting motor impairment in early Parkinson's disease via natural typing interaction with keyboards: Validation of the neuroQWERTY approach in an uncontrolled at-home setting. $J$ Med Internet Res 20, e89.

[31] Bhidayasiri R, Sringean J, Anan C, Boonpang K, Thanawattano C, Ray Chaudhuri K (2016) Quantitative demonstration of the efficacy of night-time apomorphine infusion to treat nocturnal hypokinesia in Parkinson's dis- 
ease using wearable sensors. Parkinsonism Relat Disord 33, S36-S41.

[32] Wallace R, Abbott C, Gibson-Horn C, Skubic M (2013) Inhome measurement of the effect of strategically weighted vests on ambulation. Conf Proc IEEE Eng Med Biol Soc 2013, 949-952.

[33] Bhidayasiri R, Sringean J, Chaiwong S, Anan C, Penkeaw N, Leaknok A, Boonpang K, Saksornchai K, Rattanachaisit W, Thanawattano C, Jagota P (2017) Rotigotine for nocturnal hypokinesia in Parkinson's disease: Quantitative analysis of efficacy from a randomized, placebo controlled trial using an axial inertial sensor. Parkinsonism Relat Disord 44, 124-128.

[34] Cheng WY, Lipsmeier F, Scotland A, Creagh A, Kilchenmann T, Jin LP, Schjodt-Eriksen J, Wolf D, ZhangSchaerer YP, Garcia IF, Siebourg-Polster J, Soto J, Verselis L, Facklam MM, Boess F, Koller M, Grundman M, Monsch AU, Postuma R, Ghosh A, Kremer T, Taylor KI, Czech C, Gossens C, Lindemann M (2017) Smartphone-based continuous mobility monitoring of Parkinsons disease patients reveals impacts of ambulatory bout length on gait features. In 2017 IEEE Life Sciences Conference, pp. 166169.

[35] Lim I, van Wegen E, Jones D, Rochester L, Nieuwboer A, Willems AM, Baker K, Hetherington V, Kwakkel G (2010) Does cueing training improve physical activity in patients with Parkinson's disease? Neurorehabil Neural Repair 24, 469-477.

[36] Benka Wallén M, Dohrn I-M, Ståhle A, Franzén E, Hagströmer M (2014) Comparison of pedometer and accelerometer derived steps in older individuals with Parkinson's disease or osteoporosis under free-living conditions. J Aging Phys Act 22, 550-556.

[37] Roy SH, Cole BT, Gilmore LD, De Luca CJ, Thomas CA, Saint-Hilaire MM, Nawab SH (2013) High-resolution tracking of motor disorders in Parkinson's disease during unconstrained activity. Mov Disord 28, 1080-1087.

[38] Roy SH, Cole BT, Gilmore LD, De Luca CJ, Nawab SH (2011) Resolving signal complexities for ambulatory monitoring of motor function in Parkinson's disease. Conf Proc IEEE Eng Med Biol Soc 2011, 4836-4839.

[39] Cole BT, Roy SH, De Luca CJ, Nawab SH (2014) Dynamical learning and tracking of tremor and dyskinesia from wearable sensors. IEEE Trans Neural Syst Rehabil Eng 22, 982-991.

[40] Cole BT, Roy SH, De Luca CJ, Nawab S (2010) Dynamic neural network detection of tremor and dyskinesia from wearable sensor data. Conf Proc IEEE Eng Med Biol Soc 2010, 6062-6065.

[41] Silva de Lima AL, Hahn T, W Evers LJ, de Vries NM, Cohen E, Afek M, Bataille L, Daeschler M, Claes K, Boroojerdi B, Terricabras D, Little MA, Baldus H, Bloem BR, Faber MJ (2017) Feasibility of large-scale deployment of multiple wearable sensors in Parkinson's disease. PLoS One 12, e0189161.

[42] Johansson D, Ericsson A, Johansson A, Medvedev A, Nyholm D, Ohlsson F, Senek M, Spira J, Thomas I, Westin J, Bergquist F (2018) Individualization of levodopa treatment using a microtablet dispenser and ambulatory accelerometry. CNS Neurosci Ther 24, 439-447.

[43] Liddle J, Ireland D, McBride SJ, Brauer SG, Hall LM, Ding H, Karunanithi M, Hodges PW, Theodoros D, Silburn PA, Chenery HJ (2014) Measuring the lifespace of people with Parkinson's disease using smartphones: Proof of principle. JMIR mHealth uHealth 2, e13.
[44] Raknim P, Lan KC (2016) Gait monitoring for early neurological disorder detection using sensors in a smartphone: Validation and a case study of parkinsonism. Telemed $E$ Health 22, 75-81.

[45] Ramsperger R, Meckler S, Heger T, van Uem J, Hucker S, Braatz U, Graessner H, Berg D, Manoli Y, Serrano JA, Ferreira JJ, Hobert MA, Maetzler W, Godinho C, Santos AT, Domingos J, Abreu D, Larsen F, Fagerbakke O, Akeren I, Wangen H, Maier, Scheck O, Matthews H, Isaacs T, Lewin A, Bresolin E (2016) Continuous leg dyskinesia assessment in Parkinson's disease -clinical validity and ecological effect. Parkinsonism Relat Disord 26, 41-46.

[46] Silva de Lima AL, Evers LJ, Hahn T, de Vries NM, Daeschler M, Boroojerdi B, Terricabras D, Little MA, Bloem BR, Faber MJ (2018) Impact of motor fluctuations on real-life gait in Parkinson's patients. Gait Posture 62, 388-394.

[47] Stack E, King R, Janko B, Burnett M, Hammersley N, Agarwal V, Hannuna S, Burrows A, Ashburn A (2016) Could in-home sensors surpass human observation of people with Parkinson's at high risk of falling? An ethnographic study. Biomed Res Int 2016, 3703745.

[48] Vega J (2016) Using web interaction to monitor Parkinson's disease progression through behavioural inferences on the web. In Proceedings of the 13th Web for All Conference on - W4A '16 ACM Press, New York, USA, pp. 1-3.

[49] Cavanaugh JT, Ellis TD, Earhart GM, Ford MP, Foreman KB, Dibble LE (2012) Capturing ambulatory activity decline in Parkinson's disease. J Neurol Phys Ther 36, 51-57.

[50] White DK, Wagenaar RC, Del Olmo ME, Ellis TD (2007) Test-retest reliability of 24 hours of activity monitoring in individuals with Parkinson's disease in home and community. Neurorehabil Neural Repair 21, 327-340.

[51] Cancela J, Pastorino M, Arredondo MT, Pansera M, Pastor-Sanz L, Villagra F, Pastor MA, Gonzalez AP (2011) Gait assessment in Parkinson's disease patients through a network of wearable accelerometers in unsupervised environments. Conf Proc IEEE Eng Med Biol Soc 2011, 2233-2236.

[52] Cancela J, Pastorino M, Arredondo MT, Hurtado O (2013) A telehealth system for Parkinson's disease remote monitoring. The PERFORM approach. In 2013 35th Annual International Conference of the IEEE Engineering in Medicine and Biology Society (EMBC) IEEE, pp. 74927495.

[53] Mancini M, El-Gohary M, Pearson S, McNames J, Schlueter H, Nutt JG, King LA, Horak FB (2015) Continuous monitoring of turning in Parkinson's disease: Rehabilitation potential. Neurorehabilitation 37, 3-10.

[54] Cancela J, Pastorino M, Arredondo MT, Nikita KS, Villagra F, Pastor MA (2014) Feasibility study of a wearable system based on a wireless body area network for gait assessment in Parkinson's disease patients. Sensors 14, 4618-4633.

[55] Tzallas AT, Tsipouras MG, Rigas G, Tsalikakis DG, Karvounis EC, Chondrogiorgi M, Psomadellis F, Cancela J, Pastorino M, Waldmeyer MT, Konitsiotis S, Fotiadis DI (2014) PERFORM: A system for monitoring, assessment and management of patients with Parkinson's disease. Sensors (Basel) 14, 21329-21357.

[56] Sama A, Perez-Lopez C, Rodriguez-Martin D, MorenoArostegui JM, Rovira J, Ahlrichs C, Castro R, Cevada J, Graca R, Guimaraes V, Pina B, Counihan T, Lewy 
H, Annicchiarico R, Bayes A, Rodriguez-Molinero A, Cabestany J (2014) A double closed loop to enhance the quality of life of Parkinson's Disease patients: REMPARK system. Stud Health Technol Inform 207, 115-124.

[57] Haertner L, Elshehabi M, Zaunbrecher L, Pham MH, Maetzler C, van Uem JMT, Hobert MA, Hucker S, Nussbaum S, Berg D, Liepelt-Scarfone I, Maetzler W (2018) Effect of fear of falling on turning performance in Parkinson's disease in the lab and at home. Front Aging Neurosci 10, 78 .

[58] Iluz T, Gazit E, Herman T, Sprecher E, Brozgol M, Giladi N, Mirelman A, Hausdorff JM (2014) Automated detection of missteps during community ambulation in patients with Parkinson's disease: A new approach for quantifying fall risk in the community setting. J Neuroeng Rehabil 11, 48.

[59] El-Gohary M, Pearson S, McNames J, Mancini M, Horak F, Mellone S, Chiari L (2014) Continuous monitoring of turning in patients with movement disability. Sensors 14, 356-369.

[60] Mancini M, Weiss A, Herman T, Hausdorff JM (2018) Turn around freezing: Community-living turning behavior in people with Parkinson's disease. Front Neurol 9, 18.

[61] Del Din S, Galna B, Godfrey A, Bekkers EM, Pelosin E, Nieuwhof F, Mirelman A, Hausdorff JM, Rochester L (2019) Analysis of free-living gait in older adults with and without Parkinson's disease and with and without a history of falls: Identifying generic and disease specific characteristics. J Gerontol A Biol Sci Med Sci 74, 500-506.

[62] Godfrey A, Bourke A, Del Din S, Morris R, Hickey A, Helbostad JL, Rochester L (2016) Towards holistic freeliving assessment in Parkinson's disease: Unification of gait and fall algorithms with a single accelerometer. In 2016 38th Annual International Conference of the IEEE Engineering in Medicine and Biology Society, pp. 651654.

[63] Morris R, Hickey A, Del Din S, Godfrey A, Lord S, Rochester L (2017) A model of free-living gait: A factor analysis in Parkinson's disease. Gait Posture 52, 68-71.

[64] Del Din S, Godfrey A, Galna B, Lord S, Rochester L (2016) Free-living gait characteristics in ageing and Parkinson's disease: Impact of environment and ambulatory bout length. J Neuroeng Rehabil 13, 46.

[65] Weiss A, Sharifi S, Plotnik M, van Vugt JPP, Giladi N, Hausdorff JM (2011) Toward automated, at-home assessment of mobility among patients with Parkinson disease, using a body-worn accelerometer. Neurorehabil Neural Repair 25, 810-818.

[66] Battista L, Romaniello A (2018) A novel device for continuous monitoring of tremor and other motor symptoms. Neurol Sci 39, 1333-1343.

[67] Cohen S, Bataille LR, Martig AK (2016) Enabling breakthroughs in Parkinson's disease with wearable technologies and big data analytics. Mhealth 2, 20.

[68] Das S, Amoedo B, De la Torre F, Hodgins J (2012) Detecting Parkinsons' symptoms in uncontrolled home environments: A multiple instance learning approach. Conf Proc. Annu Int Conf IEEE Eng Med Biol Soc 2012, 3688-3691.

[69] El-Gohary M, McNames J, Chung K, Aboy M, Salarian A, Horak F (2010) Continuous at-home monitoring of tremor in patients with Parkinson's disease. Anal Biomed Signals Images, 420-424.

[70] Skidmore FM, Mackman CA, Pav B, Shulman LM, Garvan C, Macko RF, Heilman KM (2008) Daily ambulatory activity levels in idiopathic Parkinson disease. $J$ Rehabil Res Dev 45, 1343-1348.

[71] van Uem JMT, Cerff B, Kampmeyer M, Prinzen J, Zuidema M, Hobert MA, Gräber S, Berg D, Maetzler W, Liepelt-Scarfone I (2018) The association between objectively measured physical activity, depression, cognition, and health-related quality of life in Parkinson's disease. Parkinsonism Relat Disord 48, 74-81.

[72] Benka Wallén M, Nero H, Franzén E, Hagströmer M (2014) Comparison of two accelerometer filter settings in individuals with Parkinson's disease. Physiol Meas 35, 2287-2296.

[73] Benka Wallén M, Franzen E, Nero H, Hagstromer M (2015) Levels and patterns of physical activity and sedentary behavior in elderly people with mild to moderate Parkinson disease. Phys Ther 95, 1135-1141.

[74] Cereda E, Pezzoli G, Barichella M (2010) Role of an electronic armband in motor function monitoring in patients with Parkinson's disease. Nutrition 26, 240-242.

[75] Hale LA, Pal J, Becker I (2008) Measuring free-living physical activity in adults with and without neurologic dysfunction with a triaxial accelerometer. Arch Phys Med Rehabil 89, 1765-1771.

[76] Lloret SP, Rossi M, Cardinali DP, Merello M (2010) Actigraphic evaluation of motor fluctuations in patients with Parkinson's disease. Int J Neurosci 120, 137-143.

[77] White DK, Wagenaar RC, Ellis TD, Tickle-Degnen L (2009) Changes in walking activity and endurance following rehabilitation for people with Parkinson disease. Arch Phys Med Rehabil 90, 43-50.

[78] Nakae H, Tsushima H (2011) Analysis of 24-h physical activities of patients with Parkinson's disease at home. $J$ Phys Ther Sci 23, 509-513.

[79] White DK, Wagenaar RC, Ellis T (2006) Monitoring activity in individuals with Parkinson disease: A validity study. J Neurol Phys Ther 30, 12-21.

[80] Pastorino M, Cancela J, Arredondo MT, Pastor-Sanz L, Contardi S, Valzania F (2013) Preliminary results of ON/OFF detection using an integrated system for Parkinson's disease monitoring. Conf Proc IEEE Eng Med Biol Soc 2013, 941-944.

[81] Perez-Lopez C, Sama A, Rodriguez-Martin D, Catala A, Cabestany J, de Mingo E, Rodriguez-Molinero A (2015) Monitoring motor fluctuations in Parkinson's disease using a waist-worn inertial sensor. Adv Comput Intell Pt I 9094, 461-474.

[82] Rodriguez-Molinero A, Perez-Lopez C, Sama A, de Mingo E, Rodriguez-Martin D, Hernandez-Vara J, Bayes A, Moral A, Alvarez R, Perez-Martinez DA, Catala A (2018) A kinematic sensor and algorithm to detect motor fluctuations in Parkinson disease: Validation study under real conditions of use. JMIR Rehabil Assist Technol 5, e8.

[83] Bayes A, Sama A, Prats A, Perez-Lopez C, CrespoMaraver M, Moreno JM, Alcaine S, Rodriguez-Molinero A, Mestre B, Quispe P, de Barros AC, Castro R, Costa A, Annicchiarico R, Browne P, Counihan T, Lewy H, Vainstein G, Quinlan LR, Sweeney D, G OL, Rovira J, Rodrigue z-Martin D, Cabestany J (2018) A "HOLTER" for Parkinson's disease: Validation of the ability to detect on-off states using the REMPARK system. Gait Posture 59, 1-6.

[84] Rodriguez-Molinero A, Sama A, Perez-Martinez DA, Perez Lopez C, Romagosa J, Bayes A, Sanz P, Calopa M, Galvez-Barron C, de Mingo E, Rodriguez Martin D, Gonzalo N, Formiga F, Cabestany J, Catala A (2015) Validation 
of a portable device for mapping motor and gait disturbances in Parkinson's disease. JMIR mHealth uHealth 3 , e9.

[85] Fisher JM, Hammerla NY, Ploetz T, Andras P, Rochester L, Walker RW (2016) Unsupervised home monitoring of Parkinson's disease motor symptoms using body-worn accelerometers. Parkinsonism Relat Disord 33, 44-50.

[86] van Wegen EEH, de Goede CJT, Kwakkel G, van Kordelaar J (2018) Sensor assisted self-management in Parkinson's disease: A feasibility study of ambulatory posture detection and feedback to treat stooped posture. Parkinsonism Relat Disord 46, S57-S61.

[87] Adams WR (2017) High-accuracy detection of early Parkinson's disease using multiple characteristics of finger movement while typing. PLoS One 12, e0188226.

[88] Giancardo L, Sánchez-Ferro A, Arroyo-Gallego T, Butterworth I, Mendoza CS, Montero P, Matarazzo M, Obeso JA, Gray ML, Estépar RSJ (2016) Computer keyboard interaction as an indicator of early Parkinson's disease. Sci Rep 6, 34468

[89] Madrid-Navarro CJ, Escamilla-Sevilla F, MinguezCastellanos A, Campos M, Ruiz-Abellan F, Madrid JA, Rol MA (2018) Multidimensional circadian monitoring by wearable biosensors in Parkinson's disease. Front Neurol 9, 157.

[90] Gros P, Mery VP, Lafontaine AL, Robinson A, Benedetti A, Kimoff RJ, Kaminska M (2015) Diagnosis of obstructive sleep apnea in Parkinson's disease patients: Is unattended portable monitoring a suitable tool? Parkinsons Dis 2015, 258418.

[91] Klingelhoefer L, Rizos A, Sauerbier A, McGregor S, Martinez-Martin P, Reichmann H, Horne M, Chaudhuri KR (2016) Night-time sleep in Parkinson's disease - the potential use of Parkinson's KinetiGraph: A prospective comparative study. Eur J Neurol 23, 1275-1288.

[92] Prudon B, Duncan GW, Khoo TK, Yarnall AJ, Burn DJ, Anderson KN (2014) Primary sleep disorder prevalence in patients with newly diagnosed Parkinson's disease. Mov Disord 29, 259-262.

[93] Sringean J, Taechalertpaisarn P, Thanawattano C, Bhidayasiri R (2016) How well do Parkinson's disease patients turn in bed? Quantitative analysis of nocturnal hypokinesia using multisite wearable inertial sensors. Parkinsonism Relat Disord 23, 10-16.

[94] Sringean J, Anan C, Thanawattano C, Bhidayasiri R (2017) Time for a strategy in night-time dopaminergic therapy? An objective sensor-based analysis of nocturnal hypokinesia and sleeping positions in Parkinson's disease. J Neurol Sci 373, 244-248.

[95] Uchino K, Shiraishi M, Tanaka K, Akamatsu M, Hasegawa Y (2017) Impact of inability to turn in bed assessed by a wearable three-axis accelerometer on patients with Parkinson's disease. PLoS One 12, e0187616.

[96] Rovini E, Maremmani C, Cavallo F (2017) How wearable sensors can support Parkinson's disease diagnosis and treatment: A systematic review. Front Neurosci 11, 555.

[97] Johansson D, Malmgren K, Alt Murphy M (2018) Wearable sensors for clinical applications in epilepsy, Parkinson's disease, and stroke: A mixed-methods systematic review. J Neurol 265, 1740-1752.

[98] Ossig C, Antonini A, Buhmann C, Classen J, Csoti I, Falkenburger B, Schwarz M, Winkler J, Storch A (2016) Wearable sensor-based objective assessment of motor symptoms in Parkinson's disease. J Neural Transm 123, 57-64.
[99] Del Din S, Godfrey A, Mazzà C, Lord S, Rochester L (2016) Free-living monitoring of Parkinson's disease: Lessons from the field. Mov Disord 31, 1293-1313.

[100] Pereira CR, Pereira DR, Weber SAT, Hook C, de Albuquerque VHC, Papa JP (2019) A survey on computerassisted Parkinson's Disease diagnosis. ArtifIntell Med $\mathbf{9 5}$, 48-63.

[101] Silva de Lima AL, Evers LJW, Hahn T, Bataille L, Hamilton JL, Little MA, Okuma Y, Bloem BR, Faber MJ (2017) Freezing of gait and fall detection in Parkinson's disease using wearable sensors: A systematic review. J Neurol 264, 1642-1654.

[102] Bhidayasiri R, Sringean J, Thanawattano C (2016) Sensorbased evaluation and treatment of nocturnal hypokinesia in Parkinson's disease: An evidence-based review. Parkinsonism Relat Disord 22, S127-S133.

[103] Dorsey ER, Vlaanderen FP, Engelen LJ, Kieburtz K, Zhu W, Biglan KM, Faber MJ, Bloem BR (2016) Moving Parkinson care to the home. Mov Disord 31, 1258-1262.

[104] Lonini L, Dai A, Shawen N, Simuni T, Poon C, Shimanovich L, Daeschler M, Ghaffari R, Rogers JA, Jayaraman A (2018) Wearable sensors for Parkinson's disease: Which data are worth collecting for training symptom detection models. NPJ Digit Med 1, 64 .

[105] Greenland JC, Williams-Gray CH, Barker RA (2019) The clinical heterogeneity of Parkinson's disease and its therapeutic implications. Eur J Neurosci 49, 328-338.

[106] Pelicioni PHS, Menant JC, Latt MD, Lord SR (2019) Falls in parkinson's disease subtypes: Risk factors, locations and circumstances. Int J Environ Res Public Health 16, E2216.

[107] Hechtner MC, Vogt T, Zöllner Y, Schröder S, Sauer JB, Binder H, Singer S, Mikolajczyk R (2014) Quality of life in Parkinson's disease patients with motor fluctuations and dyskinesias in five European countries. Parkinsonism Relat Disord 20, 969-974.

[108] Shafazand S, Wallace DM, Arheart KL, Vargas S, Luca CC, Moore H, Katzen H, Levin B, Singer C (2017) Insomnia, sleep quality, and quality of life in mild to moderate Parkinson's disease. Ann Am Thorac Soc 14, 412-419.

[109] Stefani A, Högl B (2019) Sleep in Parkinson's disease. Neuropsychopharmacology 45, 121-128.

[110] Hermanowicz N, Jones SA, Hauser RA (2019) Impact of non-motor symptoms in parkinson's disease: A PMDAlliance survey. Neuropsychiatr Dis Treat 15, 2205-2212.

[111] van Wamelen D, Leta V, Podlewska A, Trivedi D, Wan YM, Metta V, Odin P, Reichmann H, Chaudhuri KR (2019) Wearable sensor (Parkinson's Kinetigraph) and dopamine transporter imaging as potential biosignature for constipation in Parkinson's (P2.8-006). Neurology 92, 2.8-006.

[112] He L, Lee E-Y, Sterling NW, Kong L, Lewis MM, Du G, Eslinger PJ, Huang X (2016) The key determinants to quality of life in Parkinson's disease patients: Results from the Parkinson's Disease Biomarker Program (PDBP). $J$ Parkinsons Dis 6, 523-532.

[113] Espay AJ, Bonato P, Nahab FB, Maetzler W, Dean JM, Klucken J, Eskofier BM, Merola A, Horak F, Lang AE, Reilmann R, Giuffrida J, Nieuwboer A, Horne M, Little MA, Litvan I, Simuni T, Dorsey ER, Burack MA, Kubota K, Kamondi A, Godinho C, Daneault JF, Mitsi G, Krinke L, Hausdorff JM, Bloem BR, Papapetropoulos S (2016) Technology in Parkinson's disease: Challenges and opportunities. Mov Disord 31, 1272-1282.

[114] Um TT, Pfister FMJ, Pichler D, Endo S, Lang M, Hirche S, Fietzek U, Kulić D (2017) Data augmentation of wear- 
able sensor data for Parkinson's disease monitoring using convolutional neural networks. In ICMI'17: Proceedings of the 19th ACM International Conference on Multimodal Interaction, pp. 216-220.

[115] Goetz CG, Leurgans S, Hinson VK, Blasucci LM, Zimmerman J, Fan W, Nguyen T, Hsu A (2008) Evaluating Parkinson's disease patients at home: Utility of selfvideotaping for objective motor, dyskinesia, and ON-OFF assessments. Mov Disord 23, 1479-1482.

[116] (2018) National Institute For Health And Care Excellence Guide to the processes of technology appraisal.

[117] Boehme P, Hansen A, Roubenoff R, Scheeren J, Herrmann M, Mondritzki T, Ehlers J, Truebel H (2019) How soon will digital endpoints become a cornerstone for future drug development? Drug Discov Today 24, 16-19.

[118] Cheng W-Y, Scotland A, Lipsmeier F, Kilchenmann T, Jin L, Schjodt-Eriksen J, Wolf D, Zhang-Schaerer Y-P, Garcia IF, Siebourg-Polster J, Soto J, Verselis L, Martin-
Facklam M, Boess F, Koller M, Grundman M, Monsch A, Postuma R, Ghosh A, Kremer T, Taylor K, Czech C, Gossens C, Lindemann M (2017) Human activity recognition from sensor-based large-scale continuous monitoring of Parkinson's disease patients. In 2017 IEEE/ACM International Conference on Connected Health: Applications, Systems and Engineering Technologies (CHASE) IEEE, pp. 249-250.

[119] Del Din S, Godfrey A, Rochester L (2016) Validation of an accelerometer to quantify a comprehensive battery of gait characteristics in healthy older adults and Parkinson's disease: Toward clinical and at home use. IEEE J Biomed Heal Informatics 20, 838-847. 